ARTIGO N³

BAIRRO DOS ALVARENGA: DO CAOS À SUSTENTABILIDADE NEIGHBOURHOOD BAIRRO DOS ALVARENGA:

FROM CHAOS TO SUSTAINABILITY

Patrícia HELEN LiMA 


\title{
BAIRRO DOS ALVARENGA: DO CAOS À SUSTENTABILIDADE
}

\author{
Patrícia Helen Lima* \\ *Arquiteta Urbanista. Mestre em Projeto Sustentável pela FAUUSP, \\ Doutoranda em Arquitetura e Cidade pela FAUUSP \\ Coordenadora da Seção de Informação da Qualidade Ambiental da PMSBC \\ E-mail: patricia.helen.lima@usp.br
}

\begin{abstract}
RESUMO
O Bairro Dos Alvarenga, palco de emblemáticas situações no decorrer do tempo, foi progressivamente alterado estrutural e funcionalmente em função do uso e da ocupação territorial, exercendo novas dinâmicas que se inserem em realidades atuais conflitantes.

O objetivo deste artigo é apresentar a estratégia da infraestrutura verde procurando conceitua-la como agregador de diversas abordagens urbanas e, simultaneamente, evidenciar os motivos da emergência de um novo elemento estruturador na cidade. São apresentados três aspectos centrais: A caracterização da cidade por sua importante localização na região metropolitana de São Paulo e pela expressiva área ambiental que possui; Os aspectos históricos que originaram o bairro, as mudanças ao longo do tempo e, como pilar, a necessidade de se propor um conjunto de diretrizes para a área urbana frente aos novos projetos, enfatizando a construção da rede de infraestrutura verde como um sistema estrutural que possibilita as conectividades na cidade contemporânea.
\end{abstract}

Palavras-chave: infraestrutura verde, conectividade, cidade contemporânea.

\section{NEIGHBOURHOOD BAIRRO DOS ALVARENGA: FROM CHAOS TO SUSTAINABILITY}

\begin{abstract}
The Neighbourhood Bairro dos Alvarenga, scenery of emblematic situations in past time, has been gradually changed in its structure and functionality according to the
\end{abstract}


use and occupation of land, causing new dynamics that are part of current conflicting realities.

The purpose of this article is to present the strategy of green infrastructure, trying to classify it as aggregator of several urban approaches and simultaneously point out the reasons for the emergence of a new structural element in the city.

Three main aspects are presented: characterization of the city because its important location in São Paulo metropolitan region and its significant environmental area; the historical aspects of the neighbourhood origin, the changes during the times; and, as a headline, the need to propose a set of guidelines for urban area considering the new projects, with emphasis to the construction of a green infrastructure network as a structural system that enables connectivity to contemporary cities.

Keywords: green infrastructure, connectivity, contemporary city.

\section{INTRODUÇÃO}

As transformações Estruturais ocorridas no Bairro dos Alvarenga configuraram-se num primeiro momento como esforços sociais de adaptação ao transplante socioeconômico ocorrido pela efervescência da urbanização na década de 1970/1980, onde a falta de política habitacional, o paradoxo da infraestrutura urbana, a ineficiência da legislação ambiental levaram a uma ocupação predatória do território resultando no esgotamento dos padrões de ocupação, dos recursos naturais e do espaço geográfico.

Essa dinâmica se inverte na década de 2000, quando tardiamente as regras que pareciam se configurar como uma dissociação do meio físico e da organização socioeconômica começam a ser interpretadas segundo a mesma ótica e os mesmos procedimentos de produção pelos diferentes atores envolvidos. Assistimos o empenho na recondução do processo de apropriação e regulação, porém para o objetivo de alcançar uma ordenação sustentável do território é preciso construir uma metodologia que atue sobre o espaço e que considere as conquistas sociais já alcançadas, aos quais se impõem ou oferece um novo valor, num diálogo entre espaço e sociedade, onde a sociedade valorize suas relações e não haja exclusivamente sobre a materialidade. 
Isso implica em identificar as novas formas contemporâneas que conduzem a nova orientação para o ambiente urbano, considerando a complexidade dos processos estrututurais (econômico, social, cultural, político, ambiental, dentre outros) numa relação de estreita dependência, com a progressiva apropriação por parte da população em hábitos de lazer, conjugados aos serviços e aos fluxos, num sistema articulado que conecta áreas ambientais com a infraestrutura da cidade.

Dentro deste contexto, numa perspectiva integradora de organização do espaço, priorizando a qualidade ambiental, entende-se a rede de infraestrutura verde como ferramenta para conectar elementos na cidade contemporânea.

\section{CARACTERIZAÇÃO GERAL}

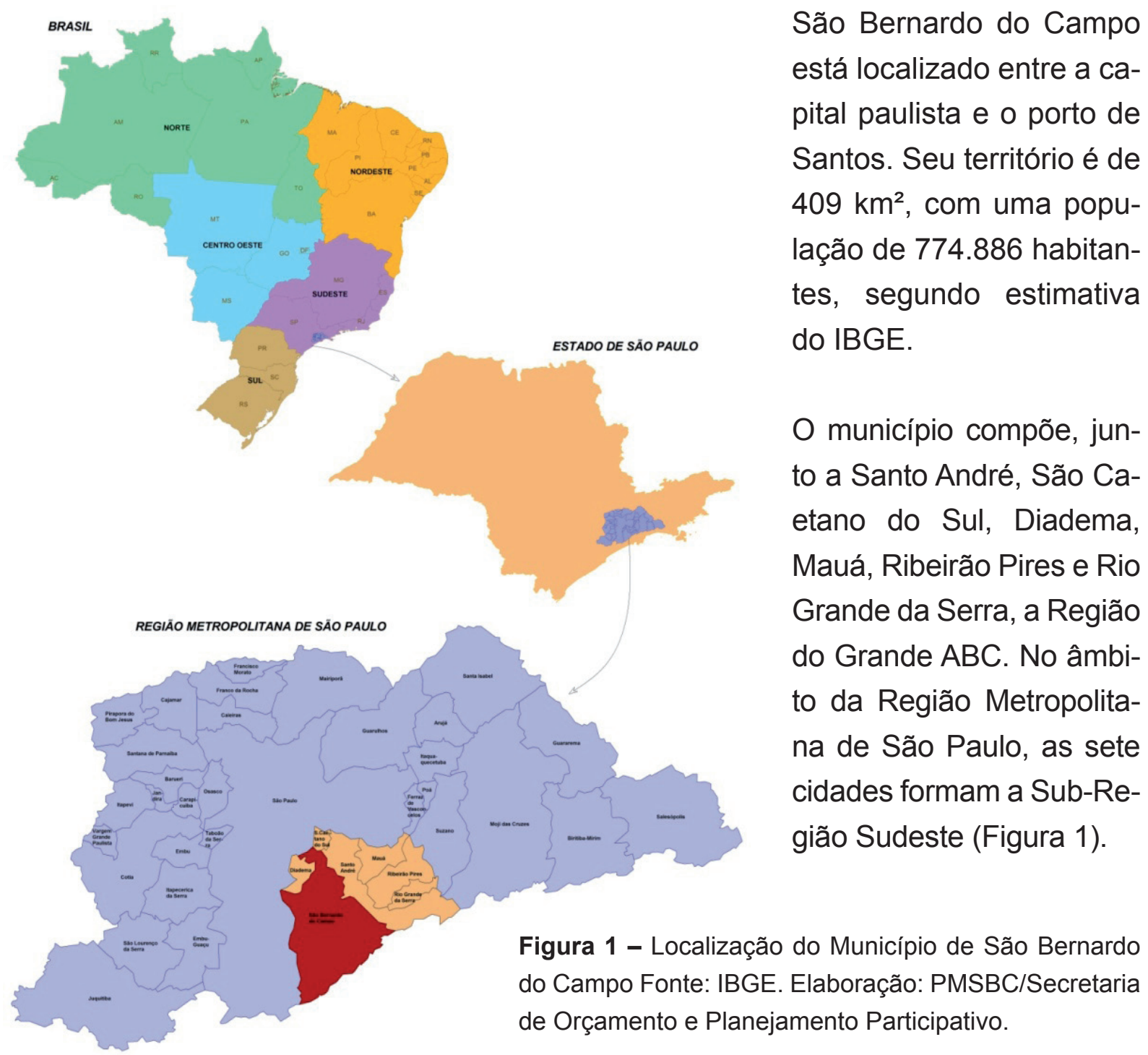


Aproximadamente $54 \%$ do território do município, ou $219 \mathrm{Km}^{2}$, está inserido na Área de Proteção e Recuperação dos Mananciais do Reservatório Billings. O espelho d'água ocupa $76 \mathrm{Km}^{2}$ (19\% da área total). Situa-se no domínio do bioma da Mata Atlântica'. Segundo o Inventário Florestal São Bernardo do Campo possui, aproximadamente, 45\% do seu território ocupado por cobertura vegetal nativa, incluindo as formações secundárias (capoeiras), totalizando 260 fragmentos remanescentes (Figura 2).

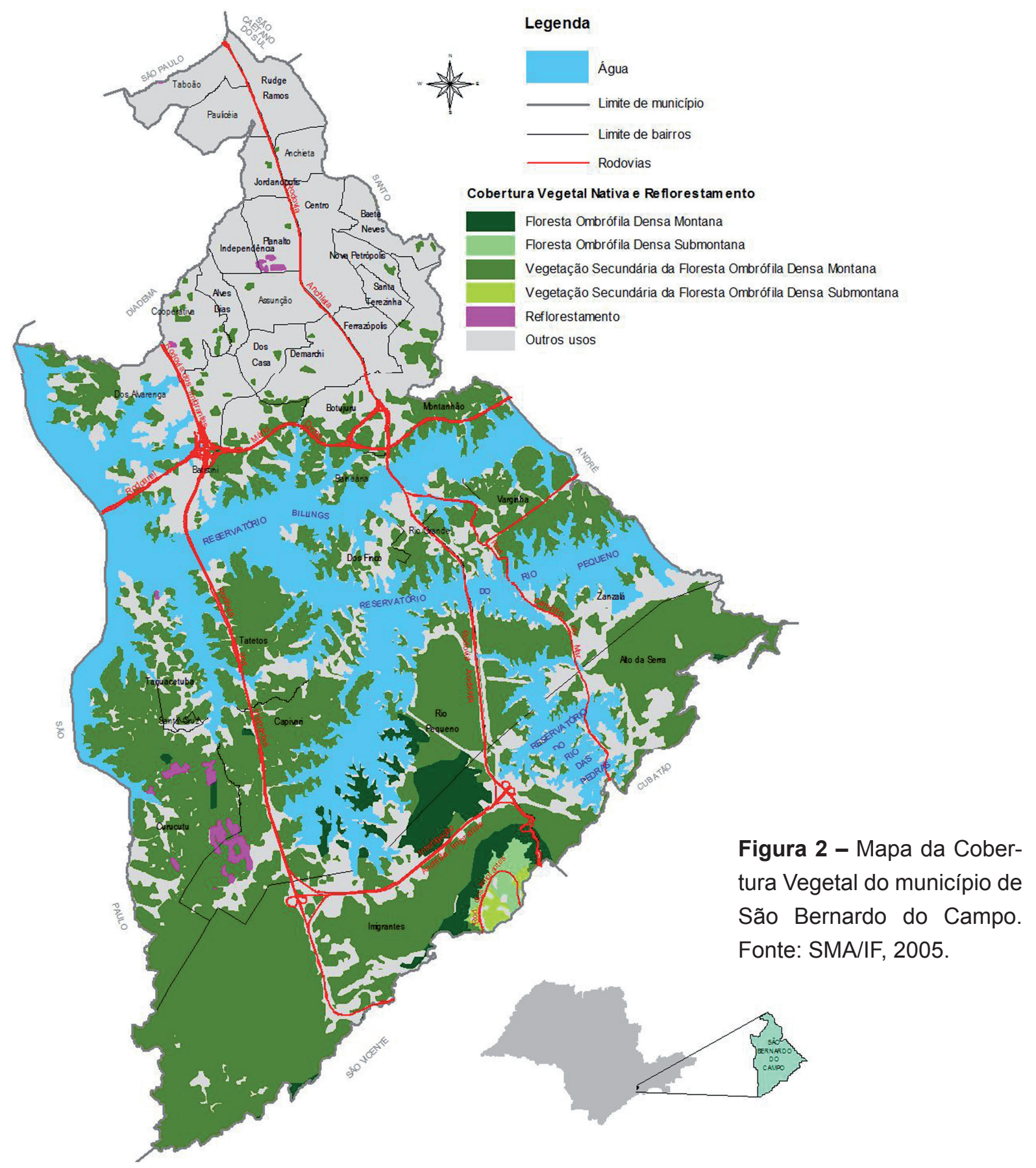

\footnotetext{
${ }^{1}$ Um dos biomas mais devastados e ameaçados, restando apenas $7 \%$ de sua extensão original e um número significativo de espécies ameaçadas de extinção (IF, 2005)
} 
A Área do Bairro Dos Alvarenga ocupa uma Área de 14,66 Km2 dentro da área de proteção aos mananciais, sendo a maior área dentre os 22 bairros da Área Urbana do Município (Figura 3).

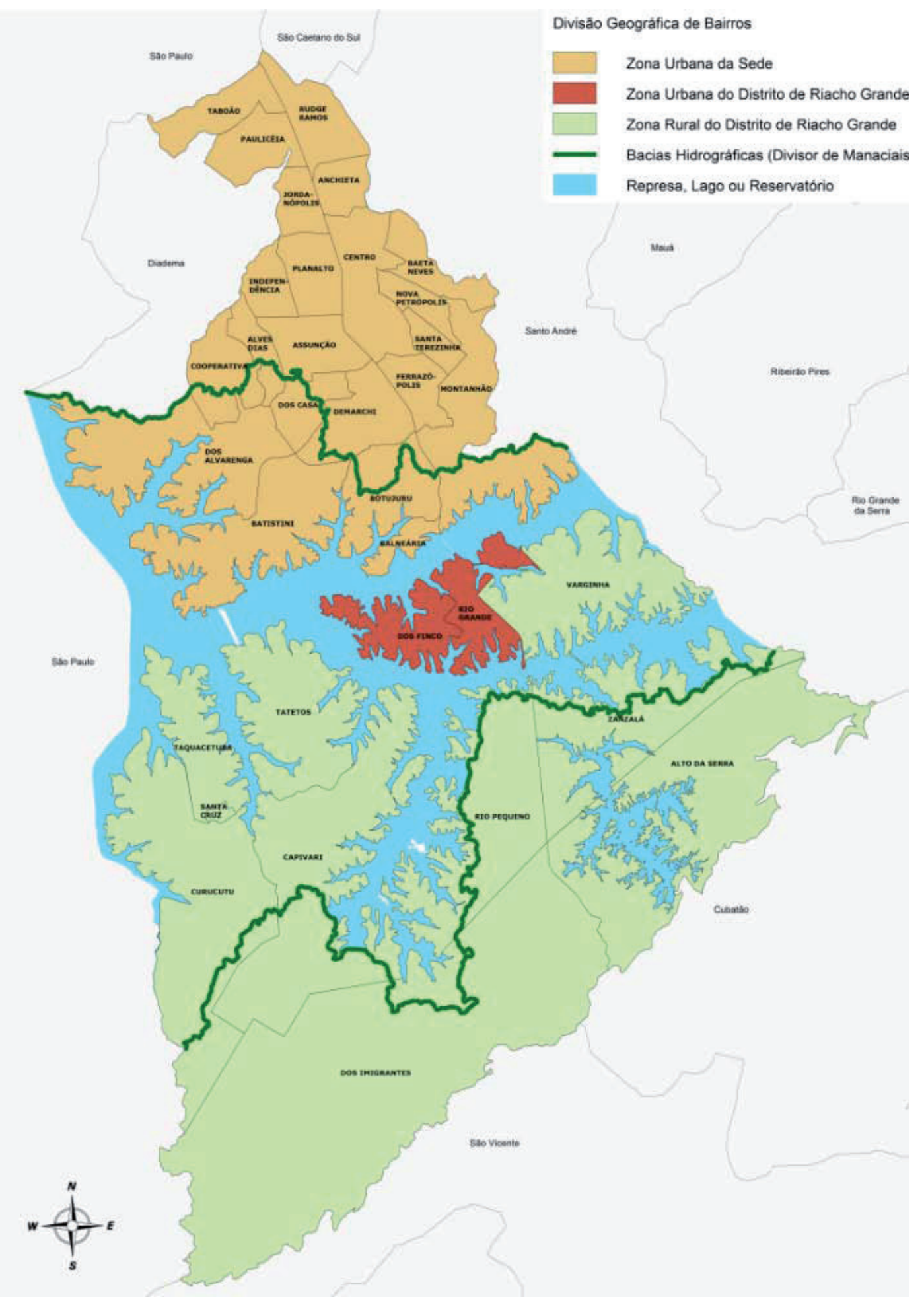

Figura 3 - Divisão de bairros em São Bernardo do Campo. Fonte: PMSBC/Secretaria de Orçamento e Planejamento Participativo. 
A ocupação no Bairro em sua maior parte é feita por loteamentos habitacionais, residindo população de baixa renda. A população residente, a taxa geométrica de crescimento anual - TGCA, Área $\left(\mathrm{km}^{2}\right)$ e densidade demográfica por bairro, São Bernardo do Campo, 2000 e 2010:

\begin{tabular}{|c|c|c|c|c|c|c|c|}
\hline \multirow[t]{2}{*}{ Bairro } & \multicolumn{2}{|c|}{ População } & \multirow[t]{2}{*}{$\begin{array}{c}\text { TGCA } \\
00 / 10\end{array}$} & \multirow[t]{2}{*}{$\begin{array}{l}\text { Área } \\
\left(\mathrm{Km}^{2}\right)\end{array}$} & \multirow{2}{*}{$\begin{array}{c}\text { Área de } \\
\text { Proteção aos } \\
\text { Mananciais }\end{array}$} & \multicolumn{2}{|c|}{$\begin{array}{c}\text { Densidade } \\
\text { Demográfica } \\
(\text { hab./km²) }\end{array}$} \\
\hline & 2000 & 2010 & & & & 2000 & 2010 \\
\hline Zona Urbana & 690.917 & 752.658 & 0,86 & 118,21 & 55,88 & 5.845 & 6.367 \\
\hline Alves Dias & 27.188 & 28.926 & 0,62 & 2,12 & 0,56 & 12.825 & 13.644 \\
\hline Anchieta & 16.770 & 15.639 & $-0,70$ & 2,30 & 0,00 & 7.291 & 6.800 \\
\hline Assunção & 41.918 & 41.828 & $-0,02$ & 4,20 & 0,05 & 9.981 & 9.959 \\
\hline Baeta Neves & 48.829 & 49.314 & 0,10 & 3,41 & 0,00 & 14.319 & 14.462 \\
\hline Balneária & 606 & 305 & $-6,64$ & 1,53 & 1,53 & 396 & 199 \\
\hline Batistini & 27.655 & 28.726 & 0,38 & 13,29 & 13,29 & 2.081 & 2.162 \\
\hline Botujuru & 11.735 & 13.283 & 1,25 & 6,60 & 4,71 & 1.778 & 2.013 \\
\hline Centro & 44.231 & 48.802 & 0,99 & 6,74 & 0,00 & 6.563 & 7.241 \\
\hline Cooperativa & 17.364 & 25.688 & 3,99 & 4,84 & 1,87 & 3.588 & 5.307 \\
\hline Demarchi & 24.009 & 26.517 & 1,00 & 5,64 & 0,74 & 4.257 & 4.702 \\
\hline Dos Alvarenga & 54.585 & 62.901 & 1,43 & 14,66 & 14,66 & 3.723 & 4.291 \\
\hline
\end{tabular}

Figura 4 - População nos bairros do Município. Fonte: IBGE/ Censos Demográficos. Elaboração: Secretaria de Orçamento e Planejamento Participativo.

As atividades principais de indústria, comércio e prestação de serviço no Bairro apresentaram, segundo dados da Secretaria de Finanças de São Bernardo do Campo, em 2011: Indústria: 48; Comércio, 695; Prestação de serviço, 2.696.

\section{Geomorfologia}

Conforme IPT (1999) distinguem-se cinco unidades homogêneas em termos geotécnicos e geoambientais no território municipal (Figura 2.5-1), as quais congregam as principais potencialidades e restrições dos terrenos frente a intervenções (Figura 4). 


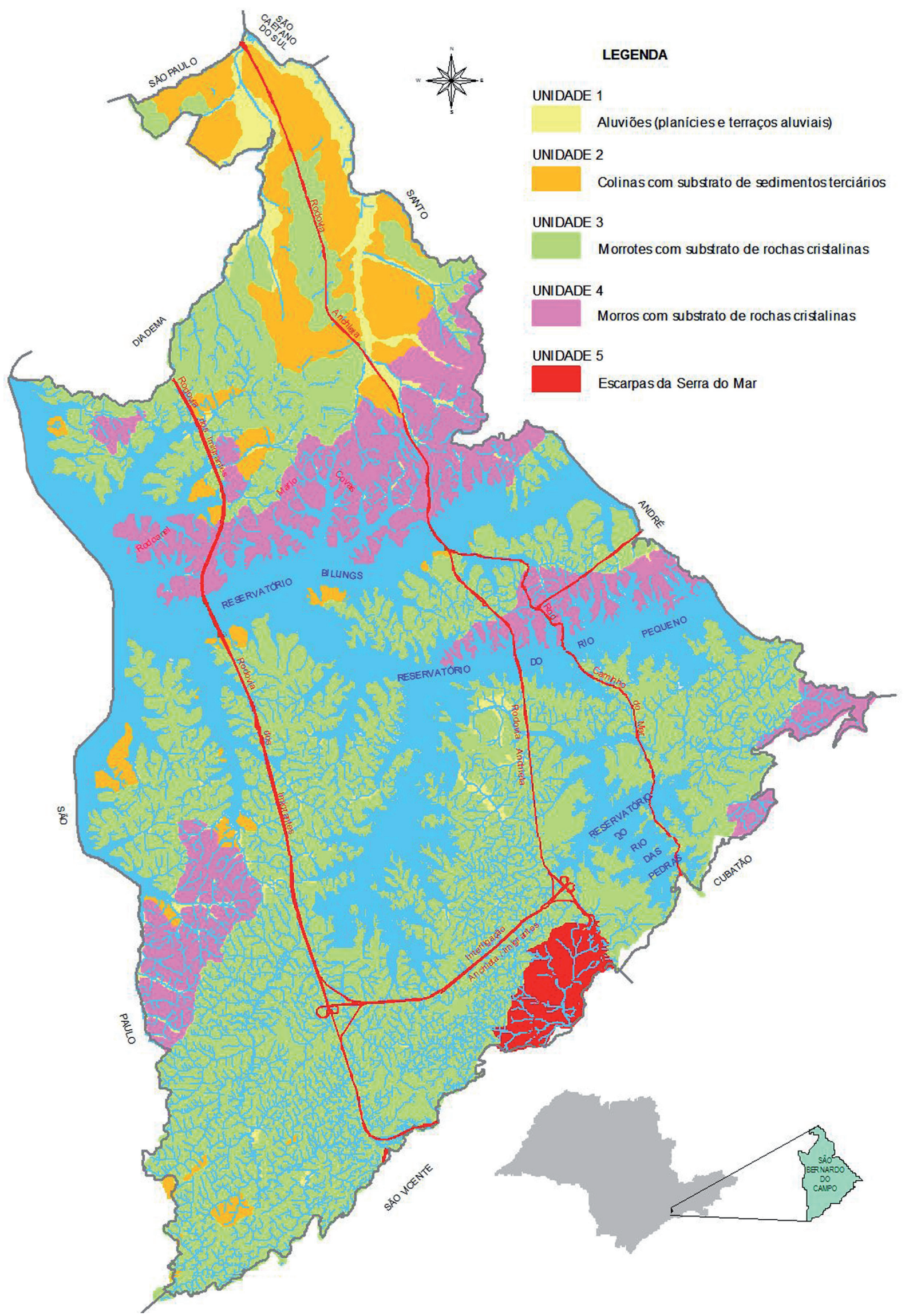

Figura 4 - Carta geotécnica do município de São Bernardo do Campo. Fonte: IPT (1999). 


\section{Hidrografia}

A bacia hidrográfica da Billings é uma sub-bacia do Alto Tietê. A oeste faz limite com a bacia hidrográfica da Guarapiranga e, ao sul, com a Serra do Mar. Os principais tributários formadores da bacia hidrográfica da Billings são: Rio Grande ou Jurubatuba; Ribeirão Pires; Rio Pequeno; Rio Pedra Branca; Rio Taquacetuba; Ribeirão Bororé; Ribeirão Cocaia; Ribeirão Guacuri; Córrego Grota Funda e Córrego Alvarenga (Figura 5).

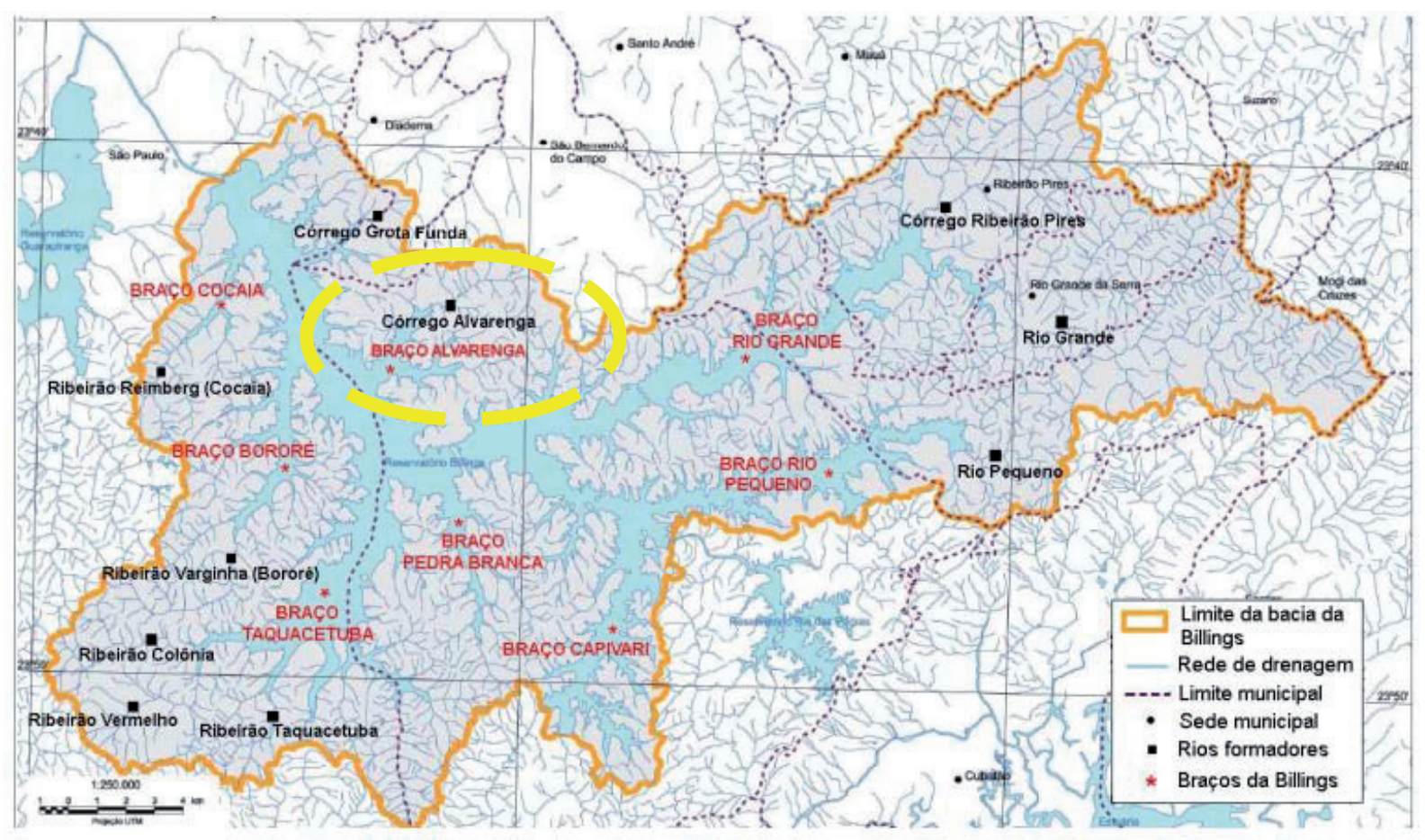

Figura 5 - Bacia Hidrográfica da Billings, municípios limítrofes, principais rios formadores e braços da represa Billings. Detalhe no Braço Alvarenga; Córrego Alvarenga. Fonte: Capobianco \& Whately (2002).

\section{Clima}

Em São Bernardo do Campo, a existência da Serra do Mar e a proximidade com o litoral criam um clima local bastante diversificado, onde a sucessão de tempos com mudanças bruscas pode ser percebida em questão de algumas horas, sobretudo na umidade relativa do ar e consequentemente na temperatura (Figura 6). Assim, fatores climáticos como pluviosidade e nebulosidade são frequentemente afetados por estas mudanças bruscas, que ocorrem de forma diversificada no território municipal, com entradas de massas de ar frio que se deslocam geralmente de sudeste para noroeste (PMSBC). 
A média de temperatura anual de São Bernardo do Campo é de $19,9^{\circ} \mathrm{C}$, com mínima média de 13,7 e máxima média de $26^{\circ} \mathrm{C}^{2}$, contudo, nas áreas urbanas densamente ocupadas a temperatura do solo atinge até $48^{\circ} \mathrm{C}$, contrastando com temperaturas de $18^{\circ} \mathrm{C}$ nas áreas de mata ao sul do município. Também é possível notar a formação de ilhas de calor, onde a temperatura é significativamente mais elevada que o entorno, em áreas industriais, totalmente impermeabilizadas e desprovidas de cobertura vegetal.

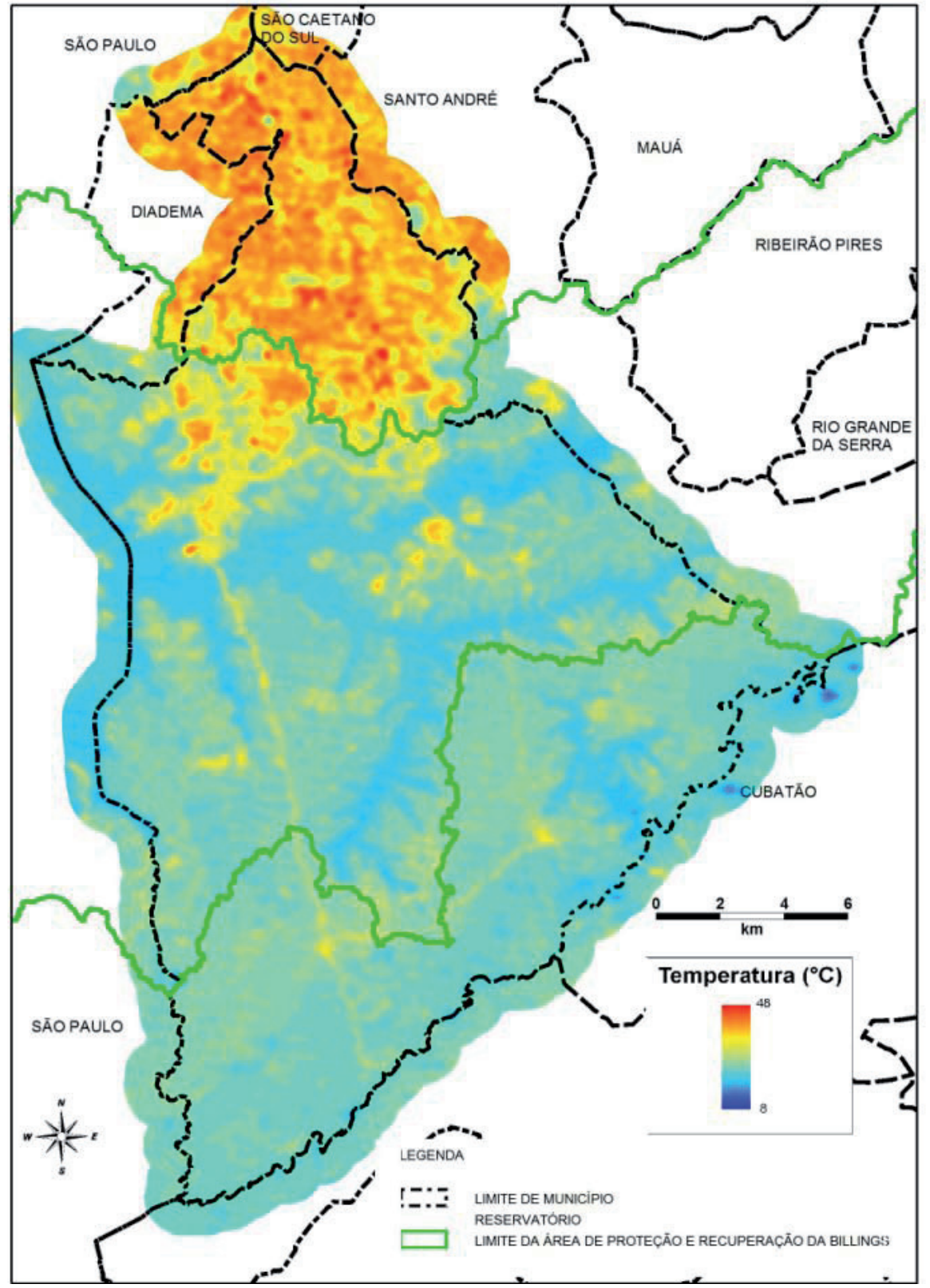

Figura 6 - Temperatura aparente da superfície (28/11/2010). Fonte: Imagem de Satélite Landsat 5 (2010), Secretaria de Gestão Ambiental de São Bernardo do Campo (2013), Secretaria Estadual de Meio Ambiente (2009).

${ }^{2}$ CEPAGRI. Clima dos municípios paulistas. (http://www.cpa.unicamp.br/outras-informacoes/clima_muni_547.html). 
O Município de São Bernardo encontra-se numa posição econômica e ambiental estratégica. O Bairro Dos Alvarenga apresenta o desafio de se situar em uma área urbana inserida nos limites da Área de Proteção e Recuperação dos Mananciais (APRM) nas sub-bacias dos ribeirões Alvarenga e das Lavras em que a preservação ambiental deve ser garantida, ainda que apresente fragmentação. Além da rica hidrografia, possui áreas de mata preservada que possibilita um conforto climático ao bairro. $\mathrm{O}$ percentual de cobertura vegetal nativa no bairro Dos Alvarenga, apesar da influência da área urbana e da rodovia Imigrantes como vetor de ocupação ainda possui significativas áreas preservadas:

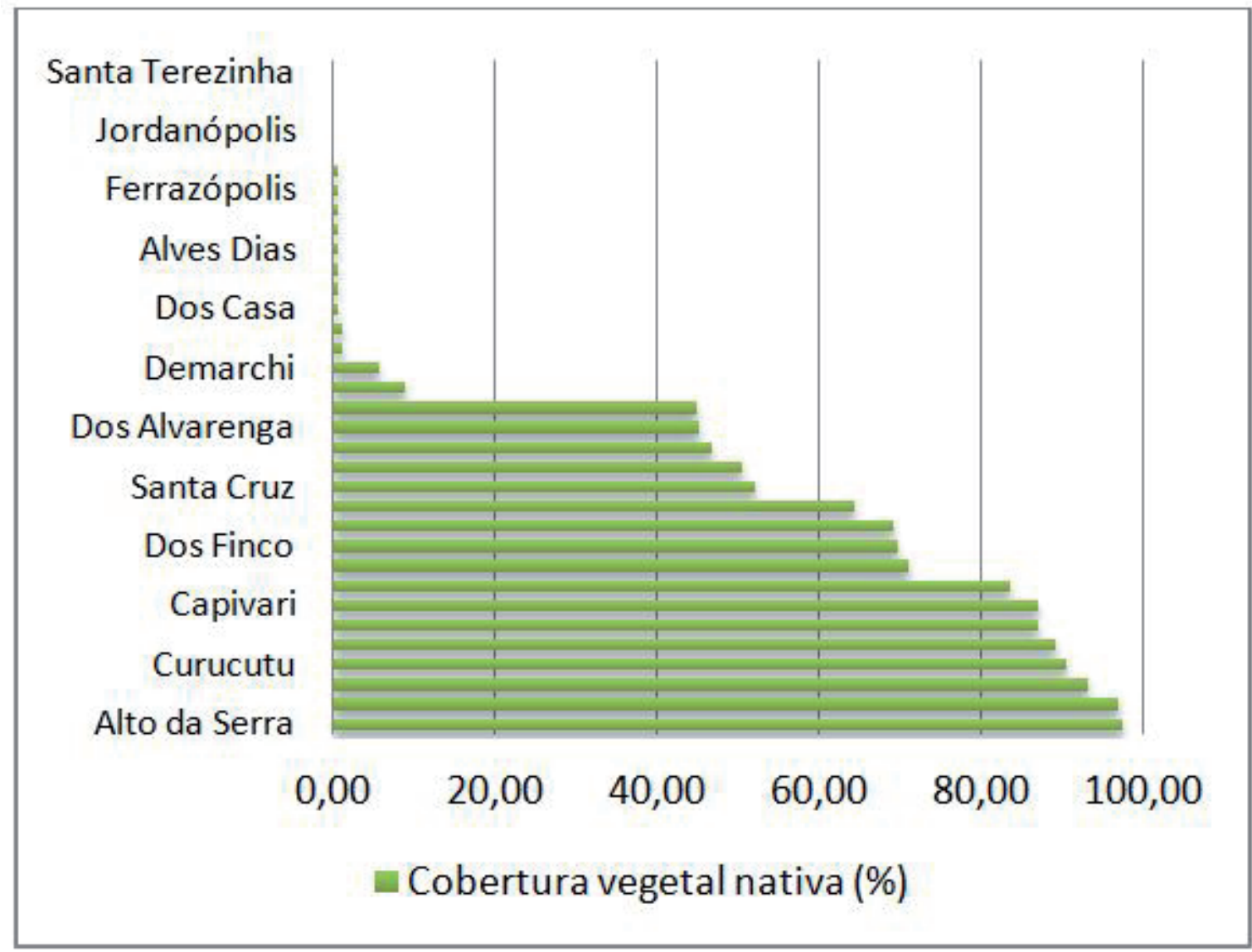

Um dos principais desafios para o local é encontrar soluções para que a conservação das condições naturais seja valorizada e estimulada como um grande potencial para o desenvolvimento urbano e para a qualidade de vida da população. Outra questão que vale ressaltar é a divisão da Bacia em sub-regiões e sub-bacias, em que a Bacia do Alvarenga encontra-se inserida totalmente no município, o que permite uma aproximação maior de um diagnóstico mais preciso da situação das áreas sujeitas a impactos negativos advindos das ações do uso do solo. 
Além da importância de suas características naturais o bairro é palco de inúmeras intervenções territoriais e carrega uma história de profundas lutas e conflitos sociais, que será apresentada à seguir.

\section{ASPECTOS HISTÓRICOS}

\section{0 - Porto Alvarenga}

O Bairro Dos Alvarenga conhecido pelo porto de água doce, com grandes quantidades de cargas transportadas por via fluvial em grandes barcos rumo ao interior da província de São Paulo e pelo descanso dos animais cargueiros aproveitando as correntezas dos rios (Figura 7).

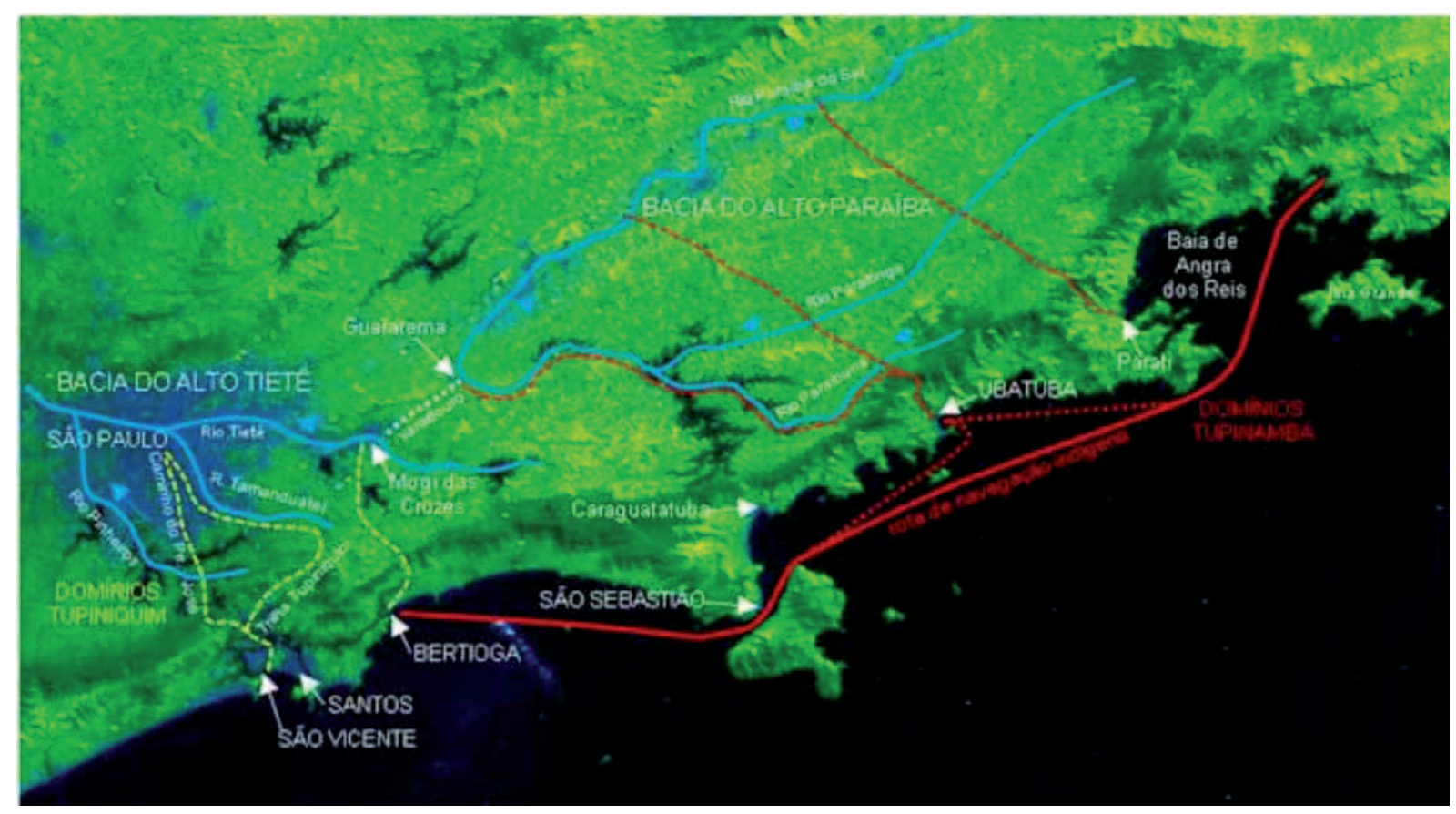

Figura 7 - Tupinambá \& Tupiniquim: Interações vivenciais e ambientais nos domínios. Infográfico sobre mapa obtido por satélite. Fonte: Instituto Nacional de Pesquisas Espaciais, Sat. Cbers, 2000. Elaborado por Rubens Giansella, 2012.

$\mathrm{Na}$ desembocadura do rio Grande com o rio Pinheiros, era feito o desembarque para Santo Amaro e para atingir São Bernardo, fizeram um porto de atracação dos Alvarengas, com início na Estrada dos Alvarengas, que veio denominar a região toda como ribeirão dos Alvarengas (Médici, 1981). 


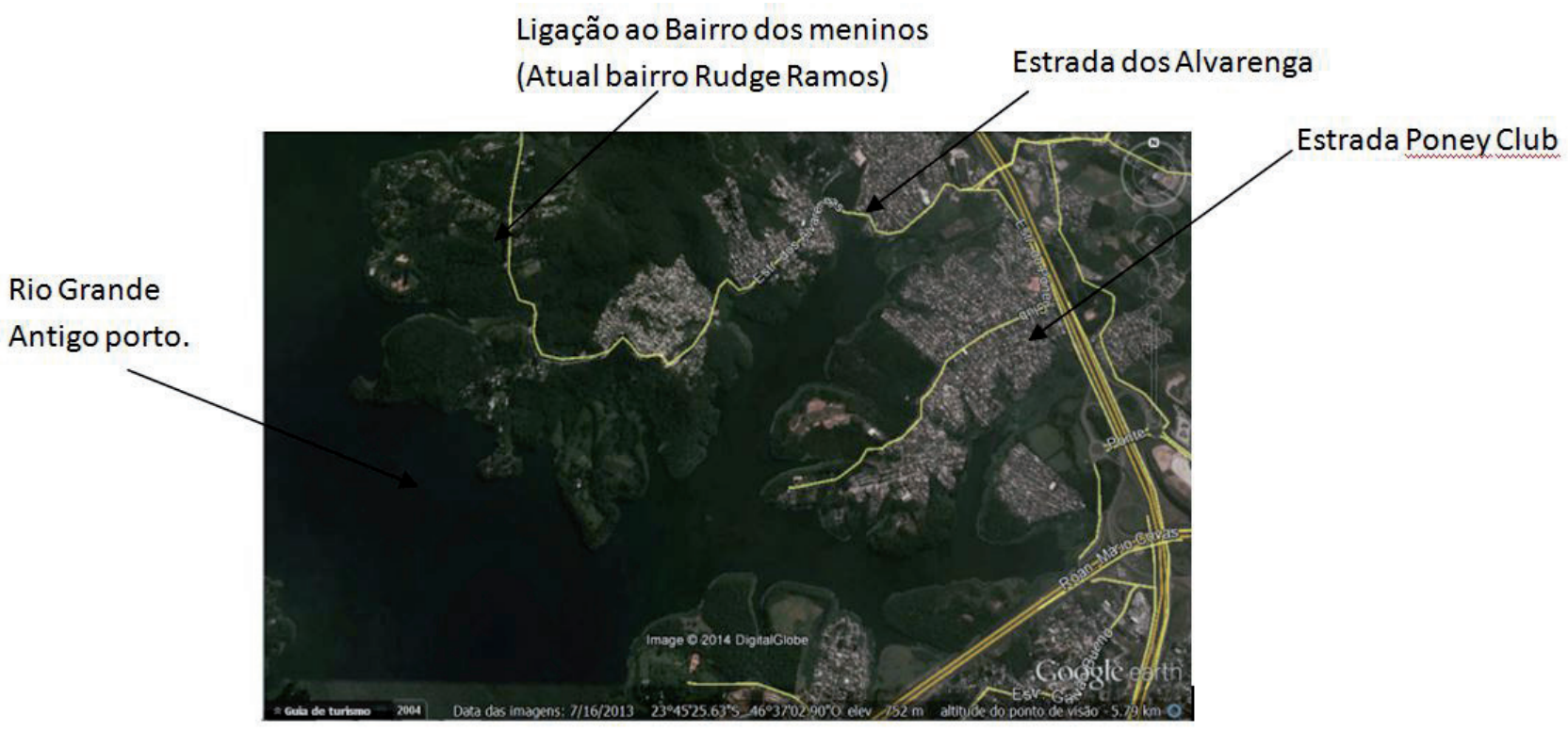

Figura 8 - Estradas de ligação no Bairro dos Alvarenga. Fonte: Google, 20014.

O acesso ao porto, portanto, se dava por três estradas (Figura 8), uma principal, que ligava São Bernardo às Alvarengas, a outra secundária, que ligava o bairro dos Meninos (hoje Rudge Ramos) às Alvarengas, e a terceira apenas variante da primeira, porque ligava S. Bernardo, em seu extremo Sul à primeira estrada. Essas três estradas se transformaram nos principais eixos de tráfego da cidade: Avenida João Firmino, Avenida Humberto de Alencar Castelo Branco e Rua Sacramento (Figura 9).

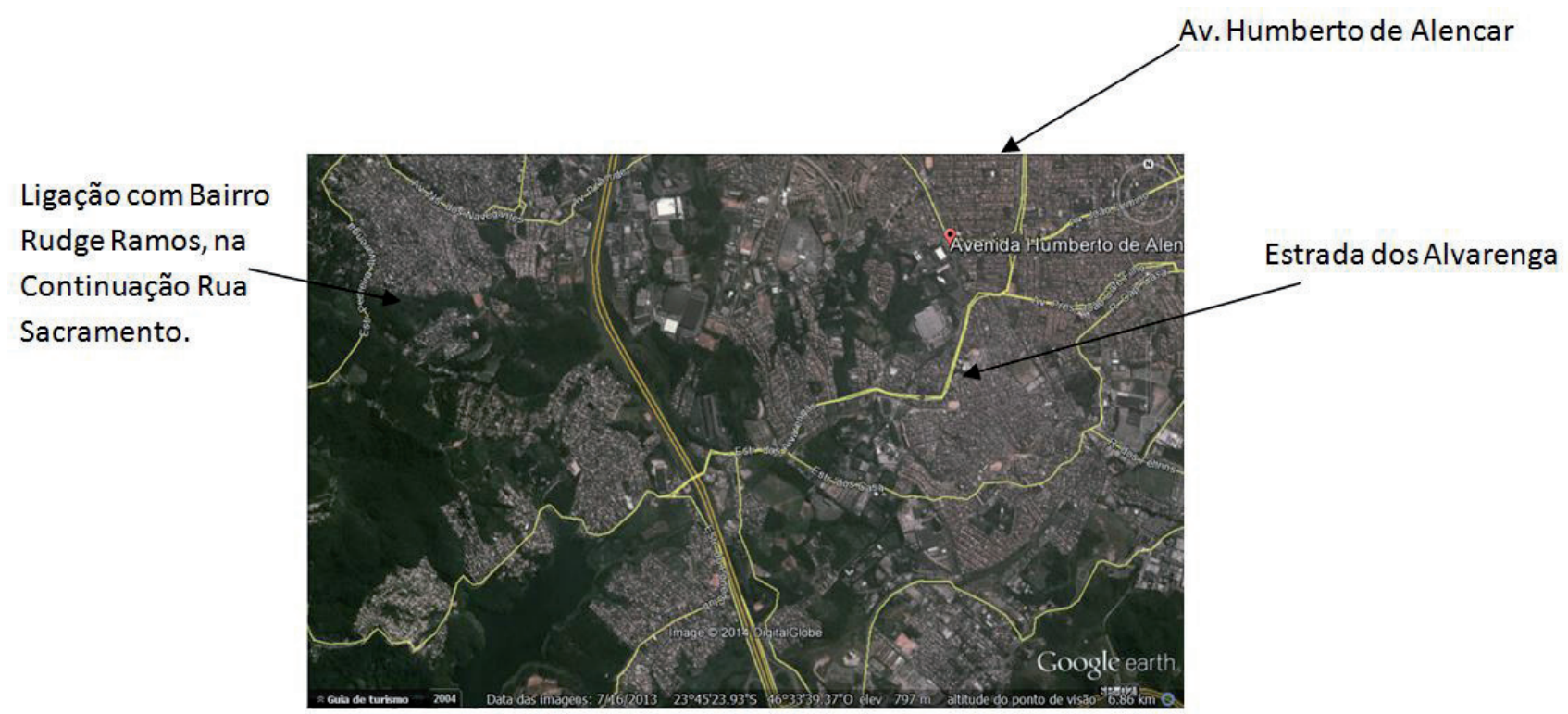

Figura 9 - Principais eixos de tráfego. Fonte: Google, 20014. 


\section{0 - Represa Billings}

Em 1924, F. Hyde e Asa White Kenny Billings, desenvolveram um projeto, conhecido originalmente como Plano Serra, e posteriormente pelo nome Billings (Figura 10). O Plano tinha como objetivo utilizar as águas da região da bacia do Alto Tietê para geração de energia elétrica. Para isso foi feita a reversão do curso do Rio Pinheiros e Tietê em direção ao reservatório Billings e deste para a Usina Henry Borden em Cubatão, transpondo os quase 800 metros de altura da Serra do Mar (http://aguasclarasdoriopinheiros.org.br).

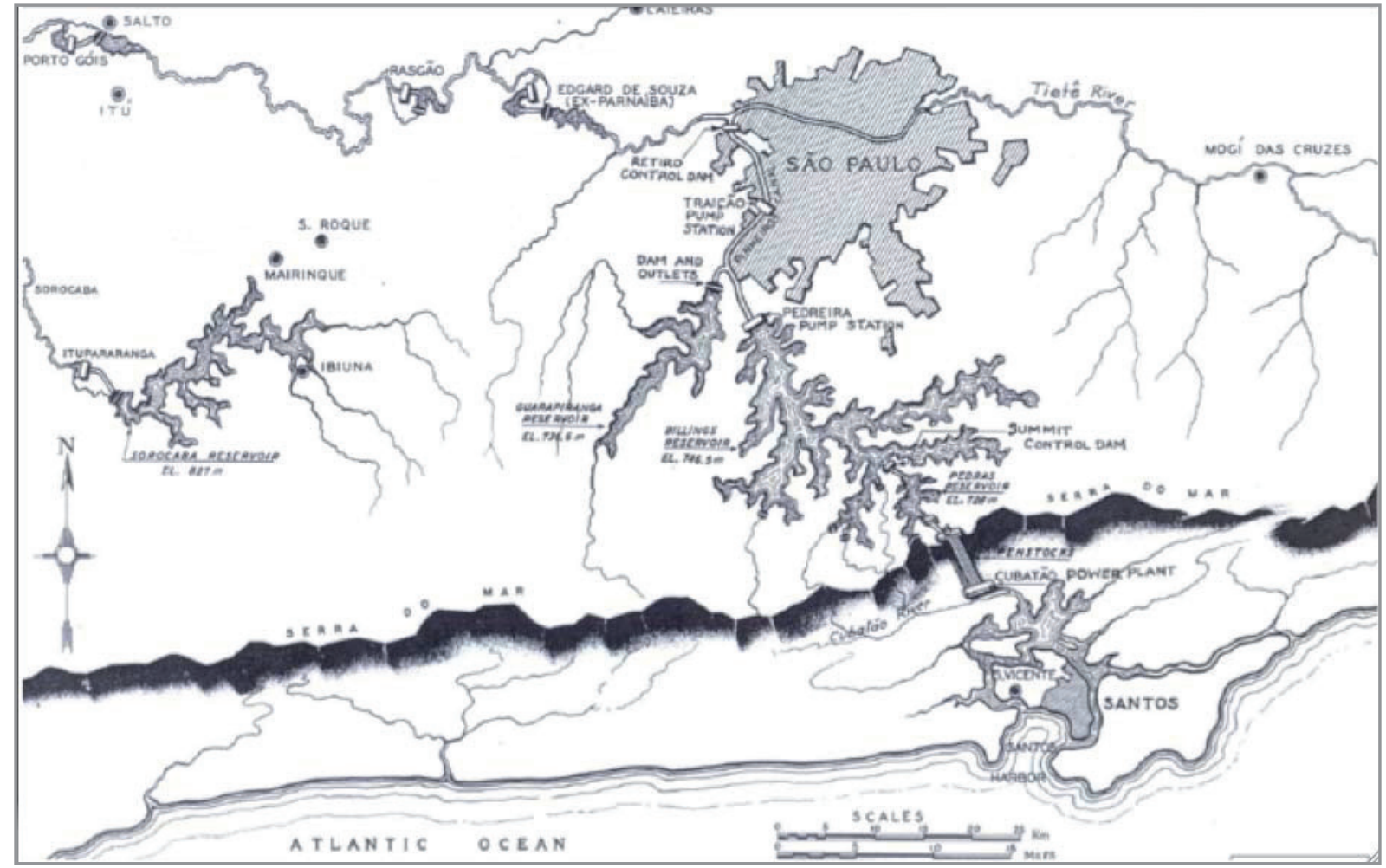

Figura 10 - Mapa do projeto Billings, período de implantação entre 1928 e 1944.

Fonte: http://aguasclarasdoriopinheiros.org.br.

O curso dos rios foi revertido através de estações elevatórias, formando um reservatório que permitiu a geração de energia. Desta forma, o rio Pinheiros foi transformado em um canal desde sua foz até a estação de bombeamento da Traição, que elevou as águas em cerca de 5 metros, conduzindo-as até a base de uma represa construída nos arredores de Santo Amaro, de onde seriam bombeadas até o Reservatório do Rio Grande, a ser formado por esta barragem (Figura 11). As águas foram conduzidas às turbinas através de tubulações para a descida da Serra (http://billingsrepresahistoria. blogspot.com.br/). 


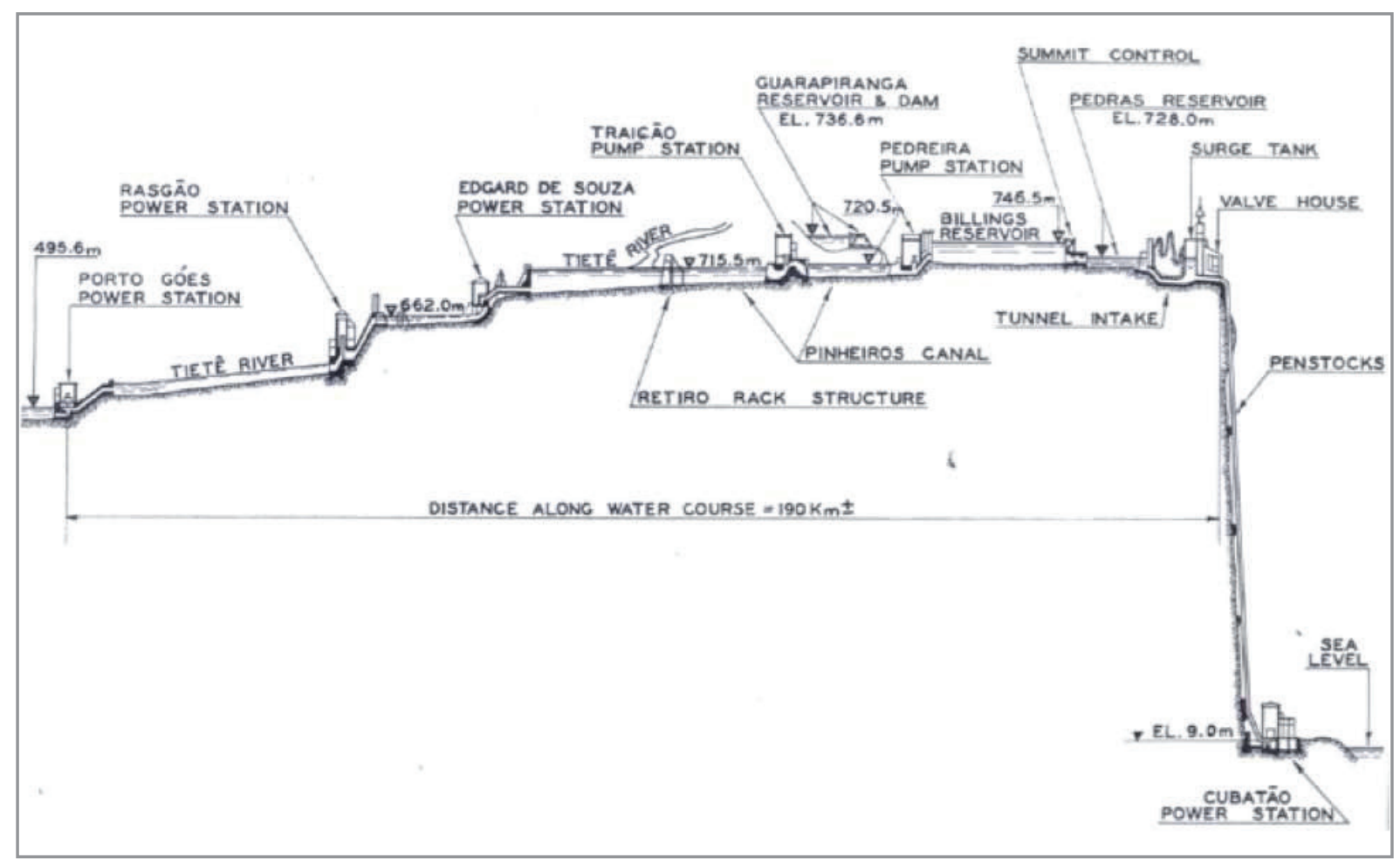

Figura 11 - Perfil do sistema da concessão do Projeto Serra, já com a usina Pedreira ("Pedreira Pump Station") - Fonte: http://aguasclarasdoriopinheiros.org.br.

A forma da apropriação da natureza a favor de interesses do uso do manancial para a geração de energia elétrica, alguns anos depois tiveram um efeito perverso sobre os rios, trazendo toda a poluição gerada por esses processos para a Billings.

\section{0 - Inauguração da Rodovia Imigrantes}

O Bairro dos Alvarenga é fragmentado pela Rodovia Imigrantes, dividindo o bairro em duas partes no sentido, construída e planejada com o objetivo de servir como amplo corredor de exportação entre o maior complexo industrial e o maior porto da América Latina.

A implantação da Rodovia apresentou mudanças significativas na dinâmica da hidrografia e morfologia do Bairro Alvarenga, além das ocupações que impactaram o território. Durante os anos de 1980 e 1990, a área dos mananciais sofreu grande expansão urbana, com ocupações irregulares e precárias, estabelecendo intensa vulnerabilidade social e ambiental (Figura 12). 

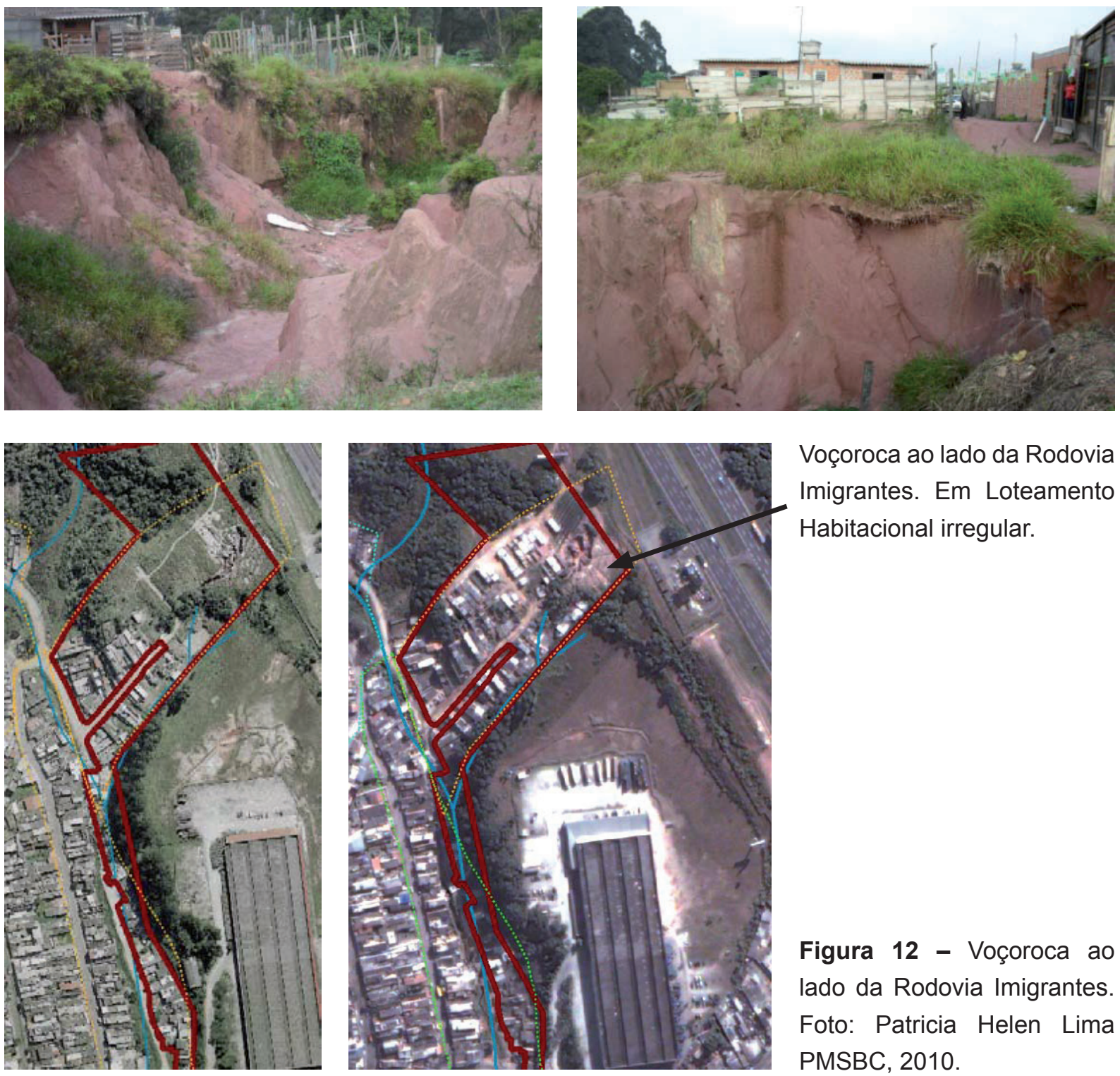

Voçoroca ao lado da Rodovia Imigrantes. Em Loteamento Habitacional irregular.

Figura 12 - Voçoroca ao lado da Rodovia Imigrantes. Foto: Patricia Helen Lima PMSBC, 2010.

\section{5 - Legislação Ambiental}

A ocupação irregular está associada ao processo de expansão urbana da Região Metropolitana de São Paulo, somando-se a isso, a implantação da rodovia Imigrantes e a instalação de indústrias automobilísticas no município (desde a construção da Via Anchieta), atraiu grande volume de trabalhadores vindos de outras regiões menos desenvolvidas do país. Essa população, sem alternativa, ocupou áreas precárias, sem quaisquer condições de infraestrutura e serviços, muitas delas localizadas em áreas de fragilidade ambiental, principalmente nas margens da represa Billings, causando sérios danos ambientais. (WHATELY,M, 2008). 
A Legislação de Proteção aos Mananciais, em vigor desde $1975^{3}$, destacou-se como importante instrumento legal implementado através de uma política metropolitana voltada prioritariamente para a preservação ambiental. Em 1976, foi promulgada a Lei Estadual n. 1172 de 17.11.1976, que delimitava as bacias hidrográficas protegidas e determinava os parâmetros urbanísticos de uso e ocupação do solo das bacias protegidas e o Decreto Estadual n. 9714 de 19.11.1976, estabelecendo as competências de órgãos envolvidos, os procedimentos de aprovação e sansões cabíveis aos infratores (Figura 13).

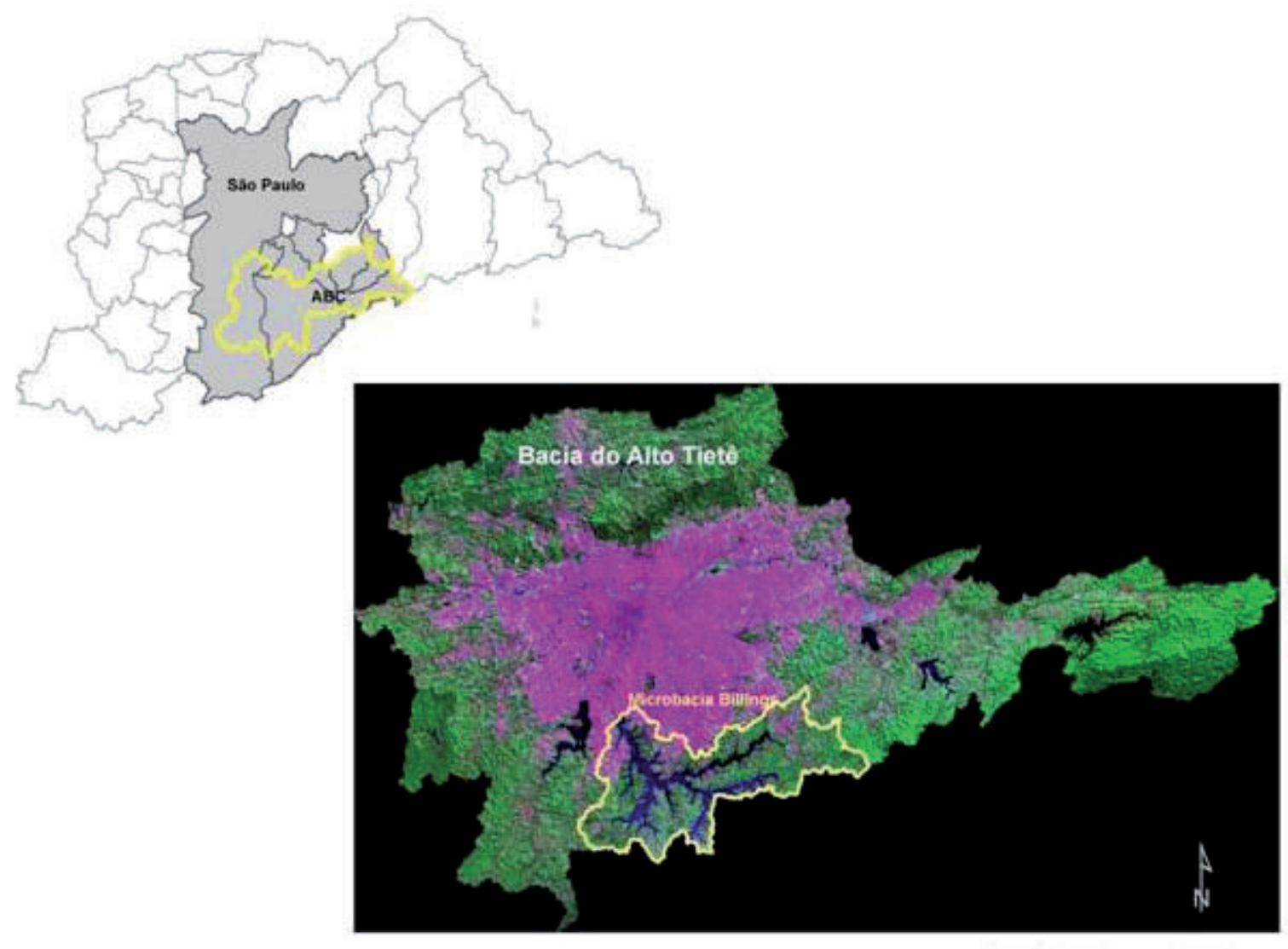

Figura 13 - Área de Proteção aos Mananciais. Fonte: Capobianco \& Whately (2002).

A Legislação, por si só, não se mostrou suficiente para preservar as bacias protegidas contra as pressões geradas pela expansão urbana da metrópole. O efeito perverso da Legislação gerou, por um lado, a desvalorização dos terrenos nas áreas protegidas, face as restrições impostas e, por outro lado, a ocupação clandestina e irregular destas áreas.

\footnotetext{
${ }^{3}$ Lei Estadual n. 898 de 08.12.1975, que disciplina o uso do solo para fins de proteção aos mananciais, cursos e reservatórios de água e demais recursos hídricos da Região Metropolitana de São Paulo e determina os cursos d'água a serem protegidos.
} 


\section{0 - Ocupação Irregular/ Degradação Ambiental}

A partir da década de 1980, a formação dos loteamentos irregulares foi intensificada na área de Proteção aos Mananciais (APM) com apropriação ilegal da terra e formação de loteamentos irregulares, bastando o desmatamento, movimentação de terra, abertura de vias e demarcação de lotes para a comercialização pelo mercado imobiliário ilegal, somando-se as construções realizadas através da autoconstrução. $A$ dimensão do espaço, a forma e o desenho urbano buscaram a possível adaptação da ocupação, em que novos elementos foram construídos de acordo com a necessidade e que causaram implicações concretas no ambiente.

Além da questão fundiária e da autoconstrução (Figura 14), destaca-se a importância das redes de infraestruturas como elementos de qualificação do ambiente urbano, explicitando contradições do ponto de vista da produção do espaço, em que as intervenções públicas aconteciam quando o loteamento estava estabelecido. A ausência da rede de coleta de esgoto era um dos principais problemas destas ocupações e os desmatamentos pelas construções.
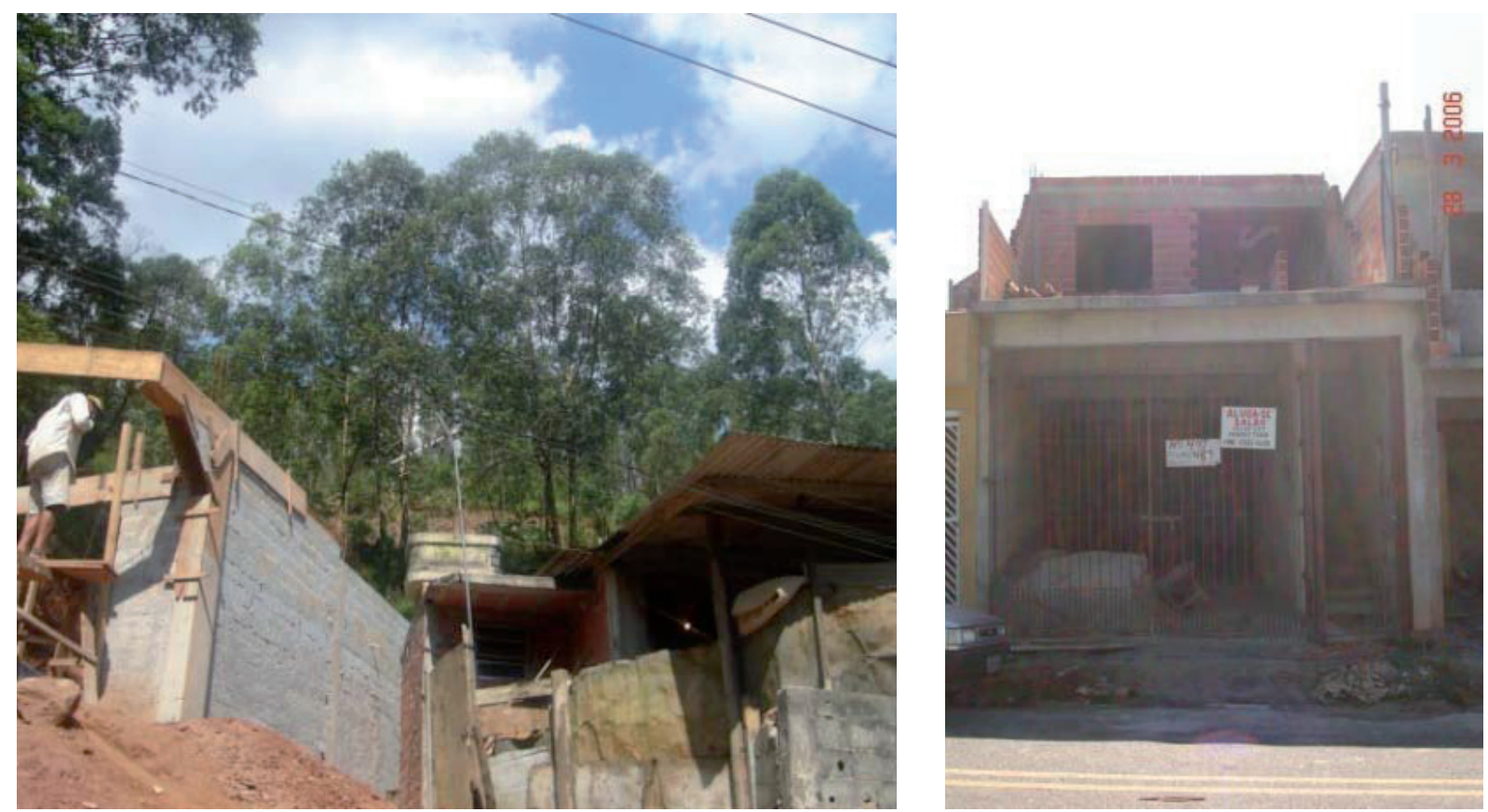

Figura 14 - Autoconstrução, aluguel de casas. Fonte: PMSBC - Fiscalização - Secretaria De Gestão Ambiental.

A via jurídica foi o caminho adotado para tentar coibir e interromper as atividades, apesar da infraestrutura básica implantada pela prefeitura em resposta a pressão social. 


\section{0 - Desfazimento das Construções}

A proliferação dos loteamentos irregulares sofreu expressiva redução somente em meados de 1998, quando do episódio de desocupação do loteamento jardim Falcão, localizado próximo ao córrego dos Alvarengas, foi demolido, onde foram derrubadas 190 casas, muitas ainda em fase de construção (Figura 15). Restava ainda a punição dos envolvidos. O efeito mais visível dessas ações foi a presença das comunidades na Promotoria e na Prefeitura, temerosas de que seus loteamentos pudessem ter o mesmo destino do loteamento demolido (Oliveira, 2007).

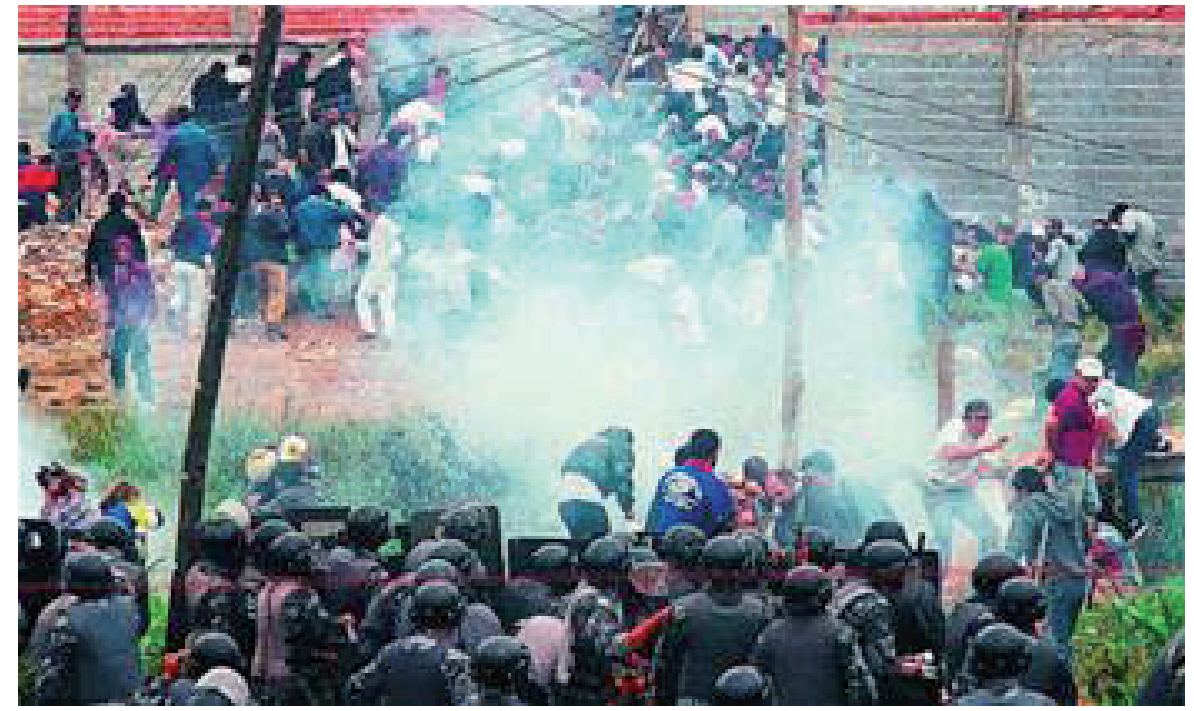

Figura 15 - Demolição Jardim Falcão. Fonte: <http://www.dgabc.com.br/Noticia/470497/apos-15-anosfamilias-do-jd-falcao-seguem-esquecidas?referencia=navegacao-lateral-detalhe-noticia>.

\section{0 - Plano Emergencial}

A revisão da Lei Estadual de Proteção aos Mananciais (Lei Estadual 9866/97) estabeleceu novas diretrizes de gestão. Apesar de continuar vigorando os mesmos parâmetros de uso e ocupação do solo, foi permitida a implementação de infraestrutura e obras de urbanização em áreas ocupadas de maior precariedade - Plano Emergencial (Decreto Estadual 43.022/98) ${ }^{4}$. O Ministério Público, na busca de alternativas para o

\footnotetext{
${ }^{4}$ Conforme a Lei Estadual n 9.866/1977, art. 47, definiu-se que: nas áreas de proteção de mananciais que tratam as Leis n 898, de 18 de dezembro de q975 e n 1172, de 17 de novembro de 1976, até que sejam promulgadas as leis específicas para as APRMs - Áreas de Proteção e Recuperação de Mananciais poderão ser executadas obras emergenciais nas hipóteses em que as condições ambientais e sanitárias apresentem riscos de vida a saúde pública ou comprometam a utilização dos mananciais para fins de abastecimento.
} 
problema da degradação ambiental elaborou o Termo de Ajustamento de Conduta (TAC), instrumento que viabilizaria a recuperação urbana ambiental compartilhada entre os diversos agentes envolvidos nas situações de irregularidade. Do ponto de vista urbanístico, foram elaboradas diretrizes de intervenção para a recuperação ambiental no contexto dos assentamentos precários em área protegida, buscando alternativas de moradia adequada, desenho urbano e infraestrutura (FERRARA, 2010).

Foi então realizado um diagnóstico, apresentado ao Ministério Público com o objetivo de implementar a infraestrutura urbana de saneamento necessária a proteção do manancial. Ações foram realizadas junto às comunidades para a elaboração dos Termos de Ajustamento de Conduta que respondessem às Ações Civis Públicas, encontradas em diferentes estágios de andamento.

O primeiro compromisso previu "congelamento" de lotes, criação de áreas de permeabilidade nas calçadas, arborização urbana e gestão de uma área de preservação permanente (ou de primeira categoria, de acordo com as leis estaduais de proteção aos mananciais) do loteamento; as discussões avançaram para o tratamento de esgotos local, custeado pelos moradores e, para a formulação de programas de geração de renda. (Oliveira, 2007).

O resultado estético proporcionado pelas calçadas gramadas estimulou a repetição espontânea pelos bairros vizinhos e o projeto transformou-se em programa de governo municipal denominado Bairros Ecológicos. O programa, mais do que estimular a execução de calçadas e arborização urbana pela população, objetivou informar e capacitar o morador da área de proteção aos mananciais sobre a importância da região para a produção de água para abastecimento (Oliveira, 2007).

Há uma repetição de padrão de calçadas adotado em outros bairros urbanizados pelo Programa Bairro Ecológico ${ }^{5}$, nos quais a PMSBC incentivou a ampliação de área permeável quebrando parte das calçadas para plantação de grama. Apesar de

\footnotetext{
${ }^{5}$ O Projeto Bairros Ecológicos foi inicialmente concebido pelo Município de São Bernardo do Campo em parceria com a Promotoria de Meio Ambiente e Habitação e Urbanismo em 1998 para organizar as ações de recuperação ambiental negociadas pelo Ministério Público (MP) com os moradores de loteamentos clandestinos, objeto de ações civis públicas. Em pouco tempo, passou a ser um instrumento de educação ambiental informal; de discussão das políticas públicas do Município para os bairros envolvidos e de capacitação dos moradores para a recuperação e gestão de seus bairros e das áreas de proteção ambiental (Rosangela Staurenghi, Promotora de Justiça de São Bernardo do Campo).
} 
insuficiente enquanto solução para o conjunto, a população demonstrou interesse em fazer pequenas ações nesse sentido. De toda maneira, a mobilidade decorrente da topografia acidentada no bairro gera grandes problemas aos pedestres, além do assoreamento decorrente das ruas de terra com grande impacto sobre os corpos d'água e represa Billings (Figura 16).
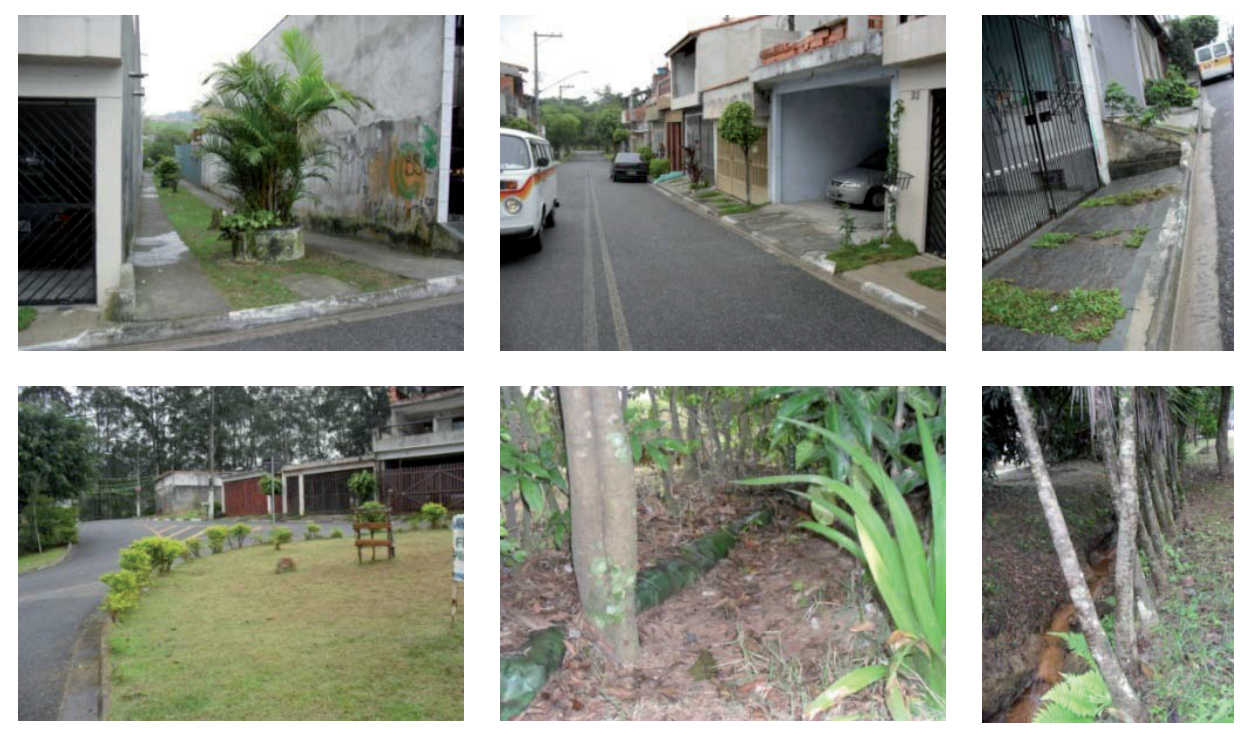

Figura 16 - Programa "Bairro Ecológico" no loteamento Senhor do Bonfim. Foto: Patricia Helen Lima PMSBC, 2010.

Todo esse processo resultou em mudanças de concepção e de ação política do poder público municipal e Ministério Público no tratamento dos loteamentos irregulares, onde a legislação de proteção aos mananciais foi pautada por lei que estabelece uma nova política.

O Bairro dos Alvarenga se destacou pela quantidade de assentamentos irregulares em área de manancial. Do total de áreas (63) indicadas no Plano Emergencial, 49 situavam-se na microbacia dos Alvarengas/Lavras. O efeito nocivo das ocupações irregulares demonstrou pela implantação desprovida de infraestrutura - abastecimento de água, esgotamento e tratamento sanitário, energia elétrica-, áreas impermeabilizadas, desmatamento, assoreamento da represa e poluição a força dos impactos ambientais. Por outro lado o bairro dos Alvarenga possui ainda hoje uma quantidade de áreas de mata entremeada à hidrografia configurando paisagens que desvendam uma nova forma urbana, onde as ações das intervenções participativas geraram espaços de convivência, resgatando relações de vizinhanças esquecidas no tempo.

A população excluída da cidade legal acredita que tem uma dívida ambiental a resgatar. E empenha-se com dedicação e seriedade neste trabalho. Assim agindo, assume um papel social atual e valorizado pela cidade legal: o de agente de recuperação e preservação ambiental (Oliveira, 2007). 


\section{9 - Lei Específica da Billings}

Em 2009 foi aprovada a Lei Específica da Billings ${ }^{6}$, que define compartimentos ambientais para o monitoramento da qualidade da água e as áreas de intervenção onde são definidas as normas ambientais e urbanísticas, definidas em três categorias: ARO - Área de Restrição a ocupação; AOD - Ocupação dirigida; ARA - Recuperação Ambiental e cria subdivisões para as Áreas de Ocupação Dirigida. Define a infraestrutura sanitária como exigência para a instalação, ampliação e regularização de edificações, empreendimentos ou atividades em toda a bacia (Figura 17).

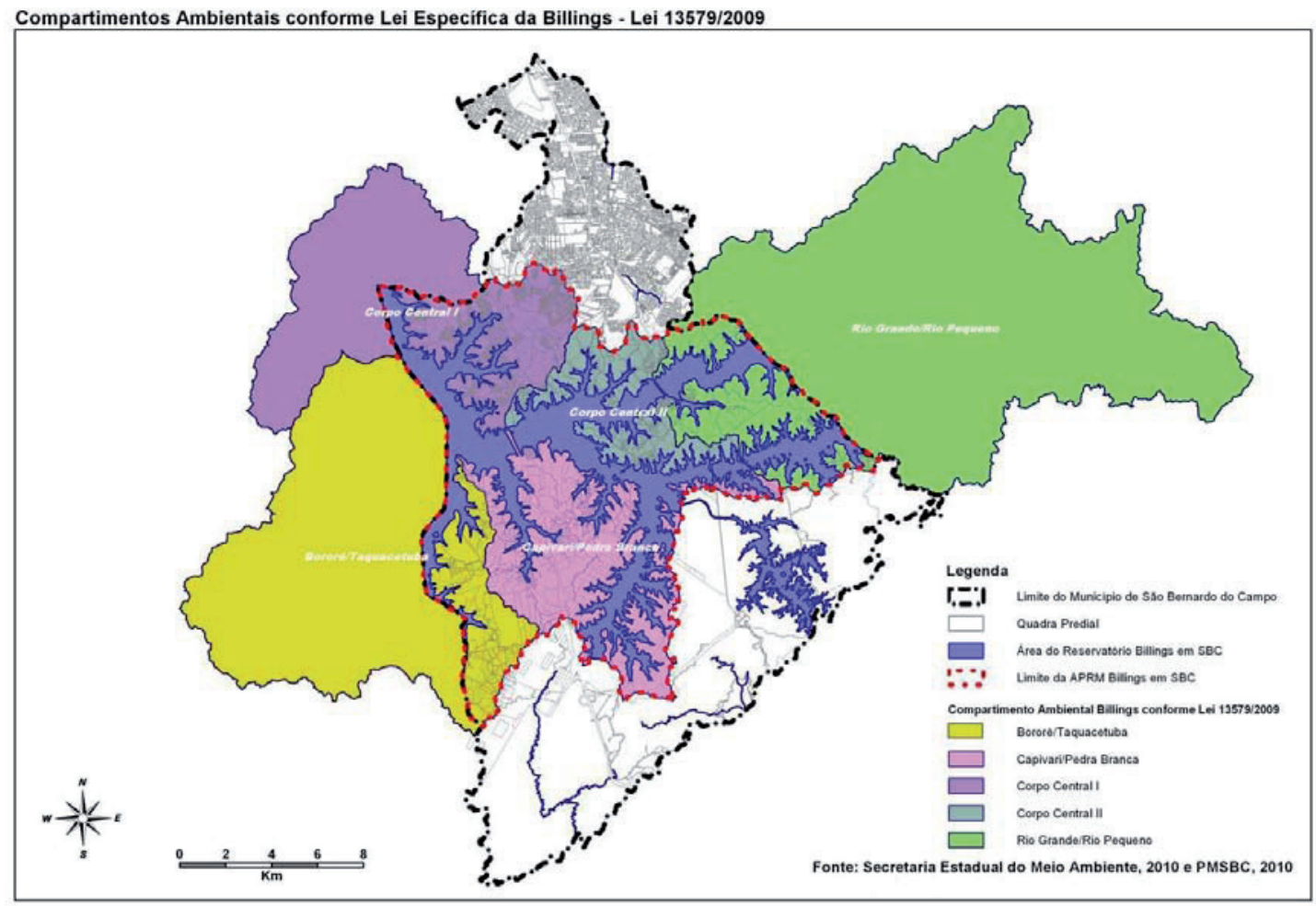

Figura 17 - Compartimentos Ambientais Lei da Billings. Fonte SMA Elaboração PMSBC - Secretaria de Gestão Ambiental.

\footnotetext{
${ }^{6}$ A Lei Específica da APRM-Billings (LE-Billings) n 13.579/2013 é um instrumento que estabelece e regulamenta o uso e ocupação da terra, tendo como objetivo central a recuperação e proteção para o abastecimento metropolitano, acatando os diferentes usos existentes na Bacia, desde que regularizados e infraestruturados nos assentamento precários e controlados nos níveis de poluição.Em seguida da obtenção do enquadramento, para a etapa de licenciamento do PRIS, o órgão ou entidade pública responsável por sua promoção deve apresentar um Plano de Urbanização, contendo o projeto completo de infraestruturas de saneamento ambiental, terraplenagem e pavimentação, paisagismo, trabalho social, circulação de transporte coletivo, proposta e estratégia de recuperação ambiental das áreas livres ou que serão desocupadas pela intervenção, proposta e estratégia de plano de regularização fundiária, e projeto de habitação de interesse social que privilegiem a melhor relação de ganho ambiental entre a área construída, gabarito e a maior taxa de permeabilidade e revegetação possíveis, devendo ser objeto de regulamentação.
} 
O Município de São Bernardo é marcado historicamente pelos caminhos de conexão com a metrópole. O caminho do Mar já deixou seu registro cortando todo o município no eixo Norte/Sul até São Paulo e para o acesso fluvial os eixos foram traçados à oeste, onde se encontra o Bairro dos Alvarenga através das 3 vias já citadas, em particular a Estrada dos Alvarenga. Nessa perspectiva é possível entender o contexto da extensão do tecido urbano de São Bernardo do Campo, que não traz o significado com a área, mas o sentido de rede de relações que subordinam este espaço à lógica da metrópole. O município, portanto, apresenta através dos eixos viários uma fragmentação do espaço que marca a cidade em diferentes épocas.

Por outro lado, o município conta com um patrimônio ambiental grandioso, que se apresenta associado ao processo de expansão urbana como parte da reprodução social em determinado momento e que impactou grandes áreas pela ocupação desmedida e quando freado este processo é que se inicia o entendimento do espaço geográfico e social como partes de uma mesma paisagem, ainda que presente a hierarquização sócio-espacial. Nesse momento, o bairro se modifica e se redefine, com novos valores.

O bairro dos Alvarenga é fruto dos diferentes momentos: da cultura pelos eixos históricos; da fragmentação pela Rodovia Imigrantes; da ocupação na esteira da expansão da metrópole com todos os efeitos da política social. A partir da apropriação ${ }^{7}$ do Bairro por seus moradores, da Legislação Ambiental incidente possibilitando iniciar uma abordagem da intervenção consciente da forma urbana.

\section{PROJETOS ATUAIS NO BAIRRO ALVARENGA}

\section{Habitação de Interesse Social}

A configuração espacial dos assentamentos existentes no Bairro dos Alvarenga apresenta diferenciação quanto à consolidação e precariedade. As ocupações mais recentes encontram-se em sua maioria ao sul, próximas a represa Billings, tendo como acesso a Estrada dos Alvarenga, conformando uma paisagem em que se encontram favelas, loteamentos adensados, pouco serviço público, mesclados a áreas vegetadas.

\footnotetext{
${ }^{7}$ A apropriação do local por seus moradores traz em si respeito e orgulho. O sentido de coletividade se manifesta e o comprometimento e as ações para a melhoria ambiental e de vida patrocinam a identidade daquele lugar, novos hábitos, novos valores, que repercutem junto à sociedade como um todo.
} 
Em 2010, foi realizado o trabalho intitulado "Mapeamento e Caracterização dos Assentamentos Precários e/ou Irregulares" por meio do estudo contratado pela Secretaria de Habitação. A partir do mapeamento realizado, foram caracterizados todos os assentamentos em seus aspectos físico-ambientais, fundiários e socioeconômicos, o que permitiu agrupá-los com tipologias de problemas comuns,orientando o planejamento das intervenções (PMSBC/SEHAB).

O Mapeamento identificou 261 assentamentos precários e/ou irregulares, sendo 66 assentamentos na macrorregião do Alvarenga (Figura 18). O Mapeamento procurou verificar a presença e as condições de atendimento nesses núcleos por parte das redes de saneamento básico e energia elétrica.

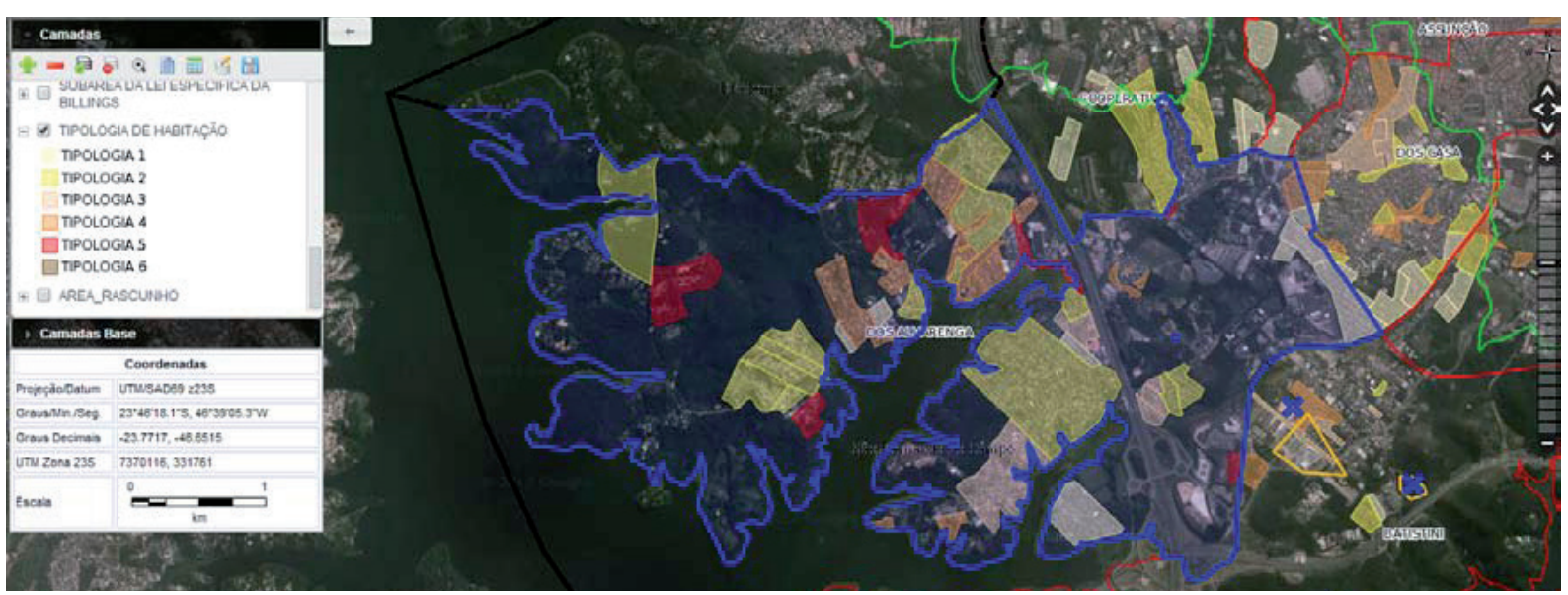

Figura 18 - Tipologias Habitacionais no Bairro dos Alvarengas. Fonte: PMSBC. Secretaria de Habitação.

No Jardim dos Químicos, por exemplo, foram realizadas obras de contenção de drenagem, no Jardim das Orquídeas, Jardim Novo Horizonte II foi doado ao Fundo Municipal de meio Ambiente valores referente a área de compensação pela implantação do loteamento. (Figura 19).
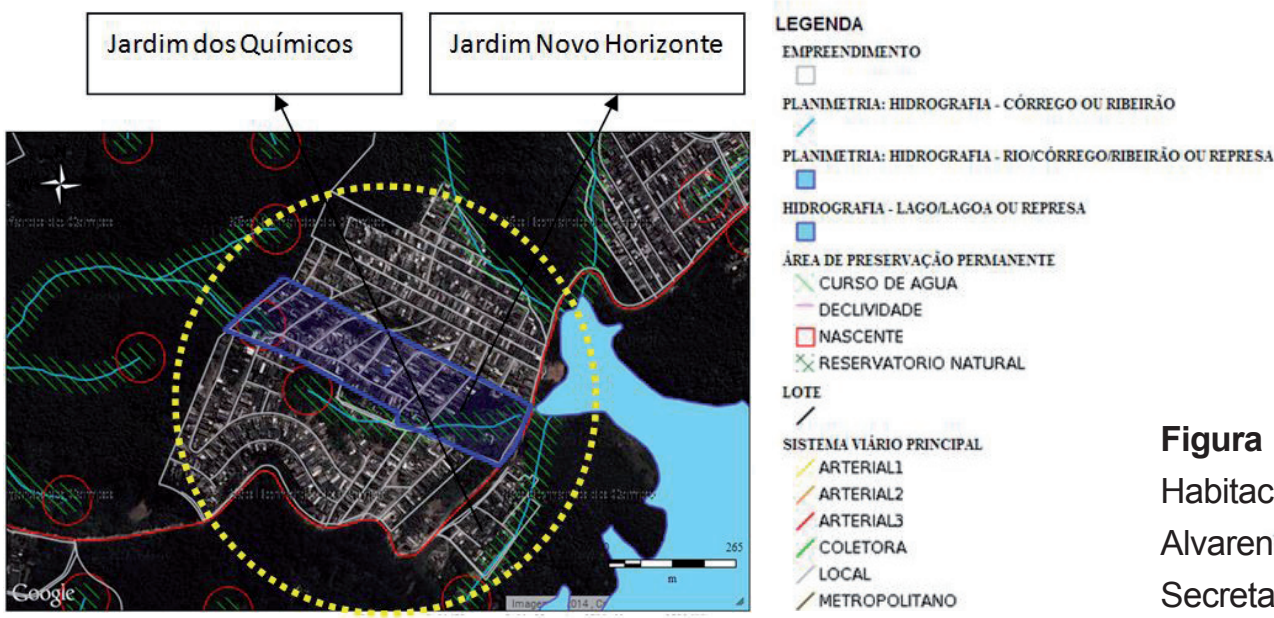

Figura 19 - Requalificação Habitacional no Bairro dos Alvarenǵa. Fonte: PMSBC. Secretaria de Habitação. 
Apesar dos avanços da política habitacional, a questão ambiental vista no conjunto das ações tem influenciado pouco na intervenção das políticas públicas, não se articulando com os demais projetos em andamento, não orientados por um plano ambiental geral, nem articulado em termos de planejamento do território.

\section{RECUPERAÇÃO DO PASSIVO AMBIENTAL}

\section{Área do antigo Lixão do Alvarenga}

O terreno de 40 mil $\mathrm{m}^{2}$ localizado próximo a represa Billings denominado Lixão do Alvarenga, recebeu resíduos orgânicos, químicos e industriais no período de 1974 a 1986. O lixão foi construído em cima de nascentes e foi desativado em 2002 por decisão da Justiça, que cobrou do município de São Bernardo do Campo e Diadema a descontaminação da área (Figura 20).

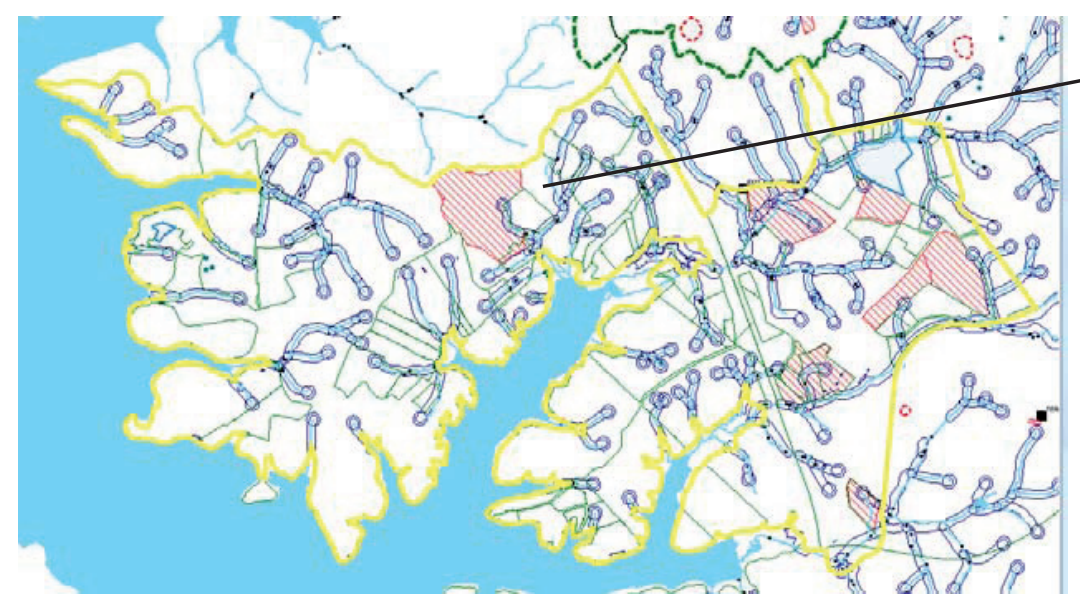

Antigo Lixão do Alvarenga

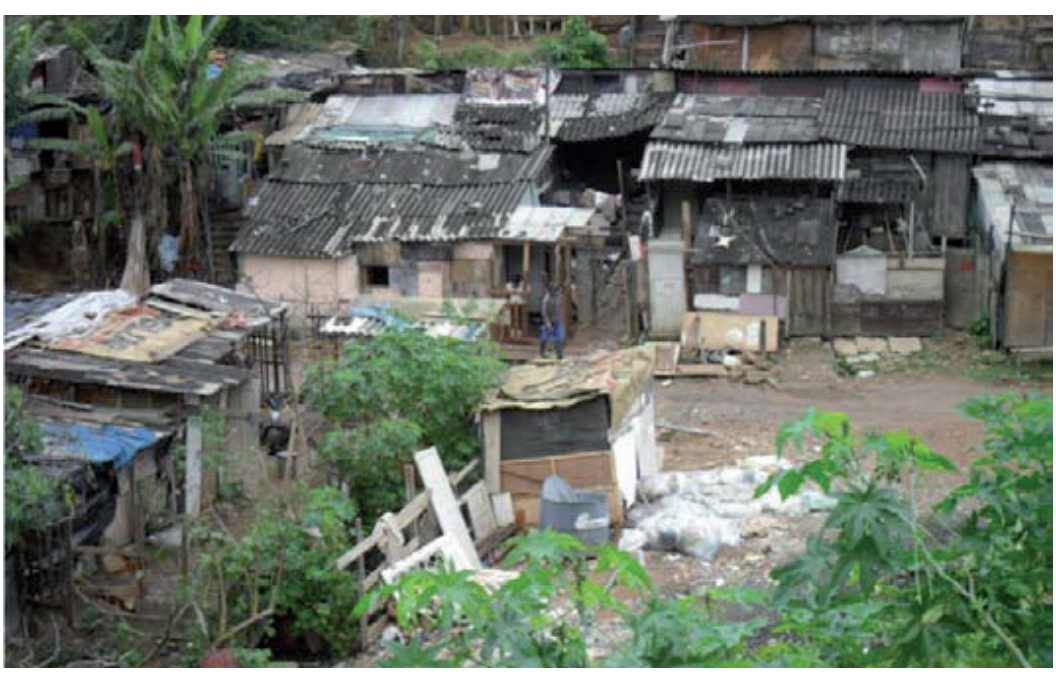

Figura 20 - Limite do Bairro dos Alvarenga com demarcação de áreas contaminadas. Detalhe na área do antigo Lixão do Alvarenga. Fonte: PMSBC.

Área do antigo Lixão do Alvarenga. Foto: Patricia Helen Lima, 2010. 
Após a recuperação da área, através da Parceria Público-Privada firmada para execução de serviços será implantada a SPAR-URE-SBC (Sistema de Processamento e Aproveitamento de Resíduos e Unidade de Recuperação Energética) e Parque Urbano, que entre outros benefícios ambientais ${ }^{8}$, deverá contribuir com as metas de reduçãode emissão de gases de efeito estufa (Figura 21).
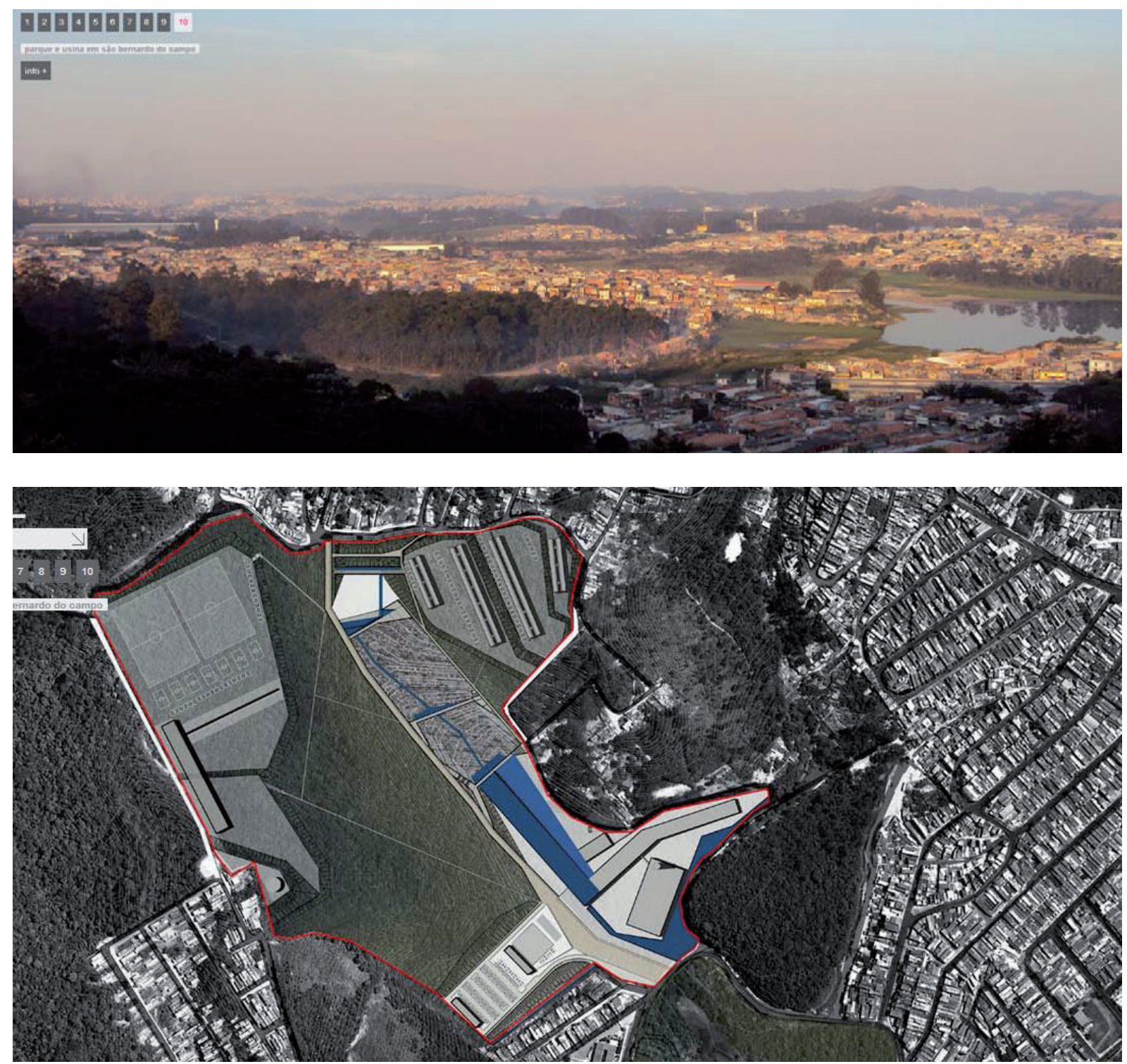

Figura 21 - Parque e usina em São Bernardo do Campo. Fonte: shundi iwamizu arquitetos associados, 2013. Disponível em http://www.siaa.arq.br/2012/07/sbc/.

\footnotetext{
${ }^{8}$ Está prevista a captação e tratamento do chorume, tratamento das águas contaminadas e a construção de um parque de cerca de 250 mil metros quadrados. Além da recuperação da área do antigo lixão, os planos de trabaIho preveem um sistema integrado de limpeza urbana, implantação de programa de coleta seletiva e de gestão de resíduos de construção civil.
} 


\section{Jardim das Oliveiras}

O assentamento irregular Jardim das Oliveiras, situado à Estrada da Cama Patente, foi ocupado sobre antigo lixão de resíduos industriais no início dos anos 90 . O local abriga cerca de 800 famílias (Figura 22).

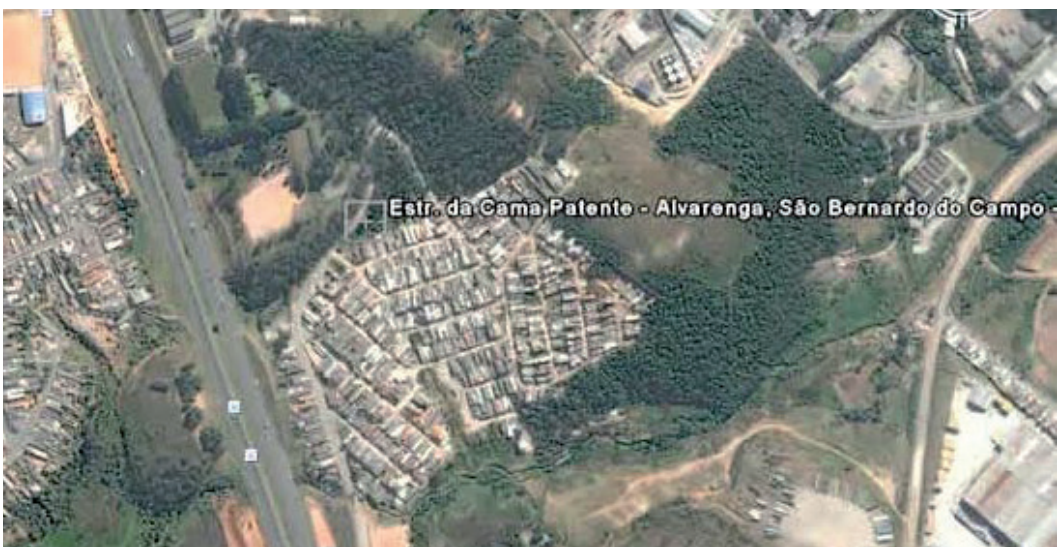

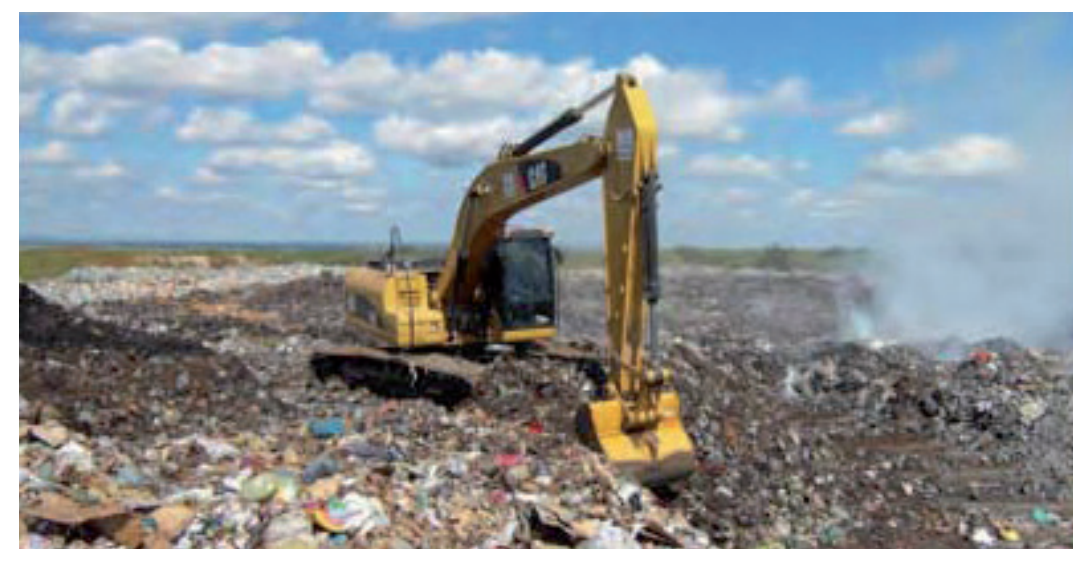

Figura 22 - Localização do assentamento Jardim das Oliveiras. Fonte: Google, 2014 e Trabalhos realizados IPT. Fonte: www.ipt.br.

Em 09/05/2008, a Prefeitura de São Bernardo apresentou à CETESB $^{9}$, relatórios elaborados pelo Instituto de Pesquisas Tecnológicas (IPT), contendo os resultados de investigação feita na área e de estudo de avaliação de risco. Foram detectados, no solo e nas águas subterrâneas, concentrações de alguns metais (como cobre, chumbo, zinco,níquel, cádmio, arsênio, cromo e mercúrio) e compostos orgânicos, em valores superiores aos valores orientadores que indicam a necessidade de intervenção na área.

\footnotetext{
${ }^{9}$ A CETESB entendeu que os estudos de investigação realizados não atenderam os seguintes requisitos: as áreas contendo resíduos não foram delimitadas; o volume de resíduos não foi quantificado; os resíduos não foram caracterizados; o número de sondagens foi insuficiente para bem caracterizar a contaminação; o solo e as águas subterrâneas não foram amostrados e analisados adequadamente e as plumas de contaminação (porções do solo e águas subterrâneas afetadas por contaminação) não foram totalmente delimitadas (CETESB, 2008).
} 


\section{INFRAESTRUTURA VIÁRIA}

\section{Programa de Transporte Urbano de São Bernardo do Campo (PTU/SBC).}

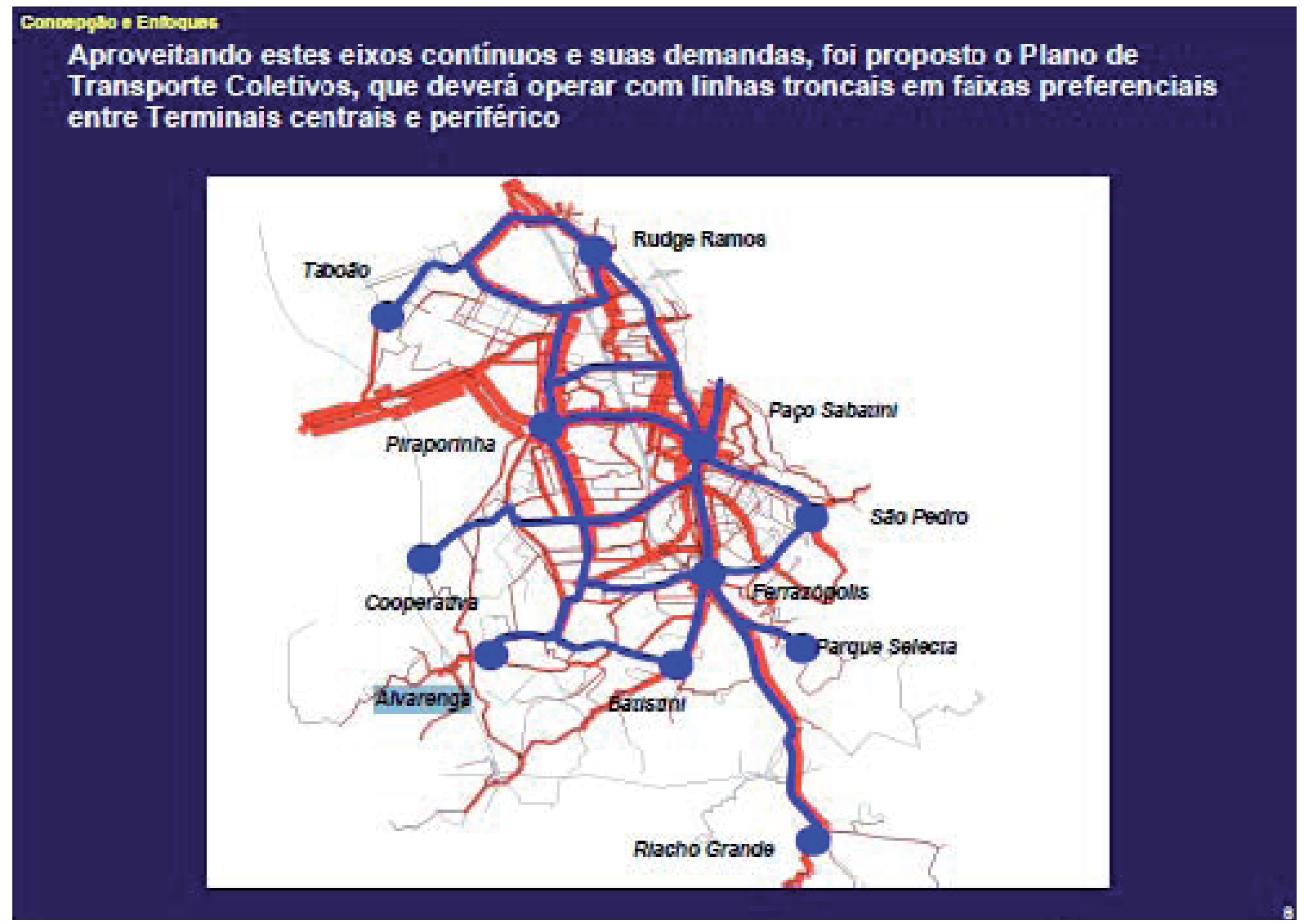

Figura 23 - Programa de Transporte Urbano de São Bernardo do Campo (PTU/SBC). Fonte: UCP BID, 2004.

O Programa de Transporte Urbano de São Bernardo do Campo - PTU/SBC ${ }^{10}$, concede a esse espaço um maior poder de articulação (Figura 23). Assim, compreende também, uma área capaz de gerar importantes fluxos de pessoas e conexões não apenas de serviços.

As avaliações conduzidas no EIA (Estudo de Impacto Ambiental) indicaram impactos na APRM - Área de Proteção e Recuperação dos Mananciais, notadamente em função das melhorias previstas para as Estradas dos Alvarenga e Galvão Bueno (Figura 24), onde se encontram os principais Passivos Ambientais.

\footnotetext{
${ }^{10}$ Conta com um Programa de Recuperação de Passivo Ambiental, que compreende medidas compensatórias aos impactos decorrentes da implementação do que não possam ser evitados, particularmente, as destinadas a mitigar impactos, diretos ou indiretos, em áreas de mananciais ou de proteção ambiental e a supressão de vegetação
} 
CARACTERIZAÇÃO AMBIENTAL DA ÁREA DE INFLUÊNCIA DO PROJETO - PAC MOBILIDADE

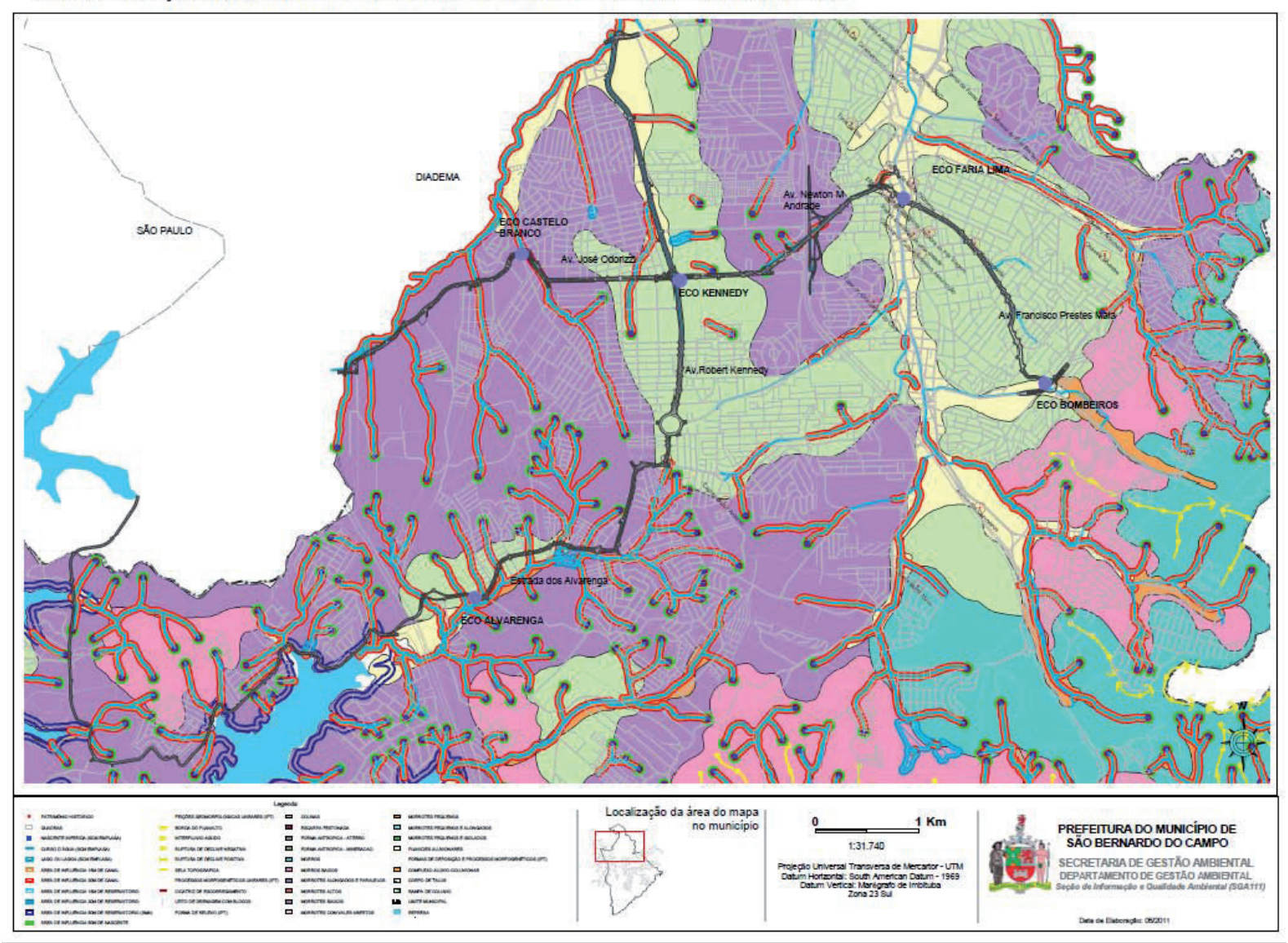

Figura 24 - Caracterização da área de influência do projeto. Principal trecho em área de morrotes baixos. Fonte: PMSBC, 2010.

Haverá a criação de uma UC na área em questão, situado ao longo de uma das vias objeto de melhoria do PTU em uma região densamente ocupada com forte pressão de expansão urbana inclusive de Diadema. Há ainda a intenção de transformar este trecho da estrada do Alvarenga em "estrada-parque" buscando a proteção ambiental desses vazios urbanos.

A possibilidade exeqüível de agregação de futuras áreas protegidas à Unidade de Conservação a ser criada potencializando o efeito-barreira à expansão urbana da região demonstra um passo no sentido das conexões propostas para a sustentabilidade das intervenções.

A conexão do Bairro dos Alvarenga ao município como um todo, cria condições de acessibilidade que foi rompida pela fragmentação da região e reforça os caminhos já utilizados, promovendo a valorização do convívio público que venham a ser criados. 


\section{Implantação da Linha 18 - Bronze - Trecho Tamanduateí - Alvarengas}

A implantação da Linha do metrô consolidará uma ligação metropolitana de média capacidade, articulando o Município de São Bernardo do Campo e região do ABC com São Paulo, utilizando como ponto de integração a Estação Tamanduateí da Linha 2 - Verde do Metrô e a Linha 10 - Turquesa da Companhia Paulista de trens Metropolitanos - CPTM. A extensão total dessa linha proposta somará aproximadamente 20 km, estando nela projetadas 18 estações, cujo traçado do eixo principal se iniciará na região do Alvarenga (Figura 25).

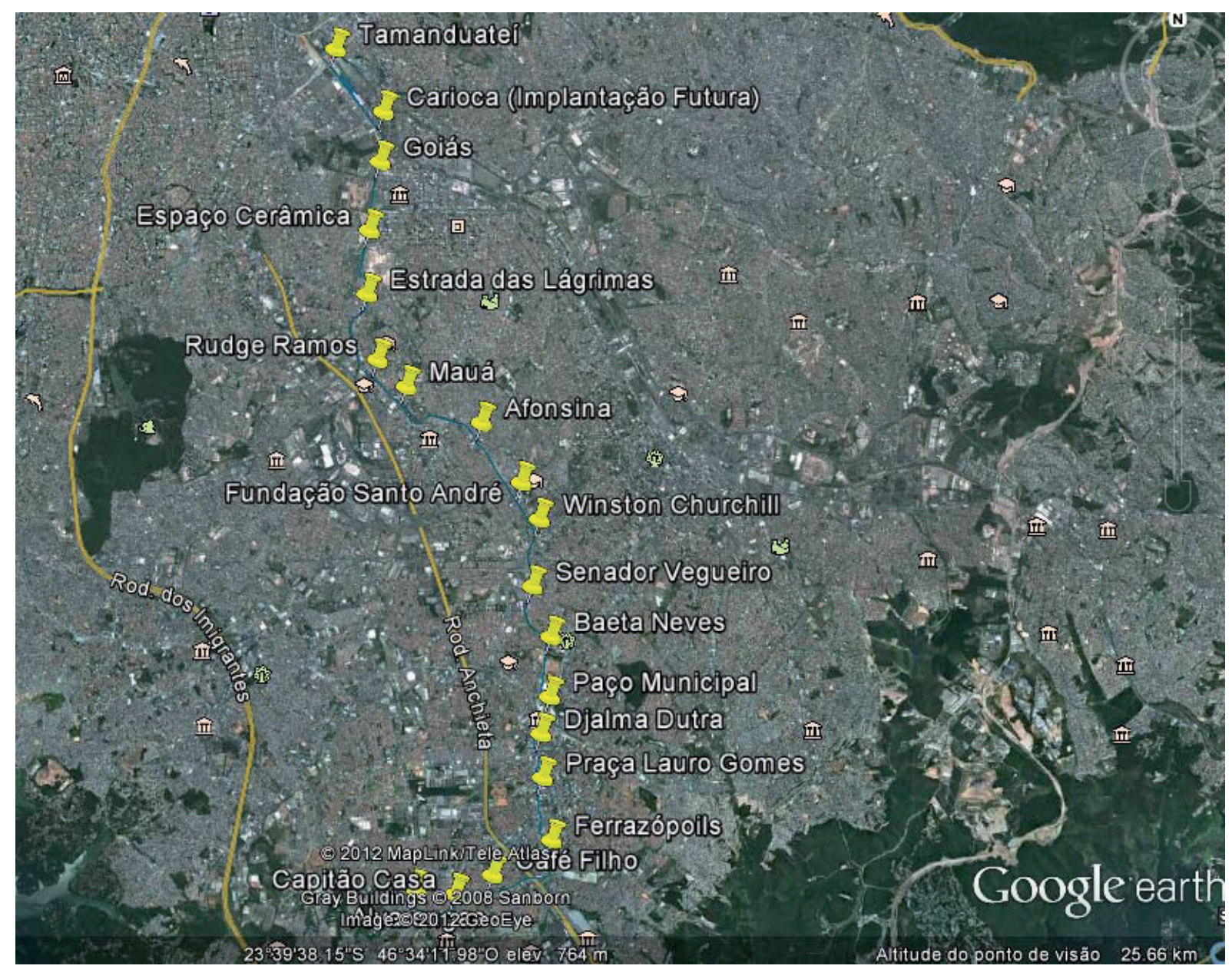

Figura 25 - Apresentação da região de inserção do Trecho Tamanduateí - Alvarengas, da Linha 18 Bronze. Fonte: Metrô. Gestão ambiental.

Esta ligação está prevista para operar com praticamente a totalidade do traçado em elevado, contando ainda, com as estações elevadas. Este projeto merece atenção especial, pois possibilitará a conexão do Bairro Dos Alvarenga à cidade e contando com áreas que possam contribuir para uso público com caráter de conservação ambiental e da paisagem local. 
Grandes projetos estão sendo implementados no bairro dos Alvarenga, como áreas de intervenção de projetos habitacionais, que mostram um novo momento de requalificação urbanística com participação social; remediação de passivos ambientais com propostas de manutenção das áreas qualificando usos e principalmente investimentos de diferentes esferas de governo em projetos estruturais de transporte. Acredita-se que com planejamento para as intervenções poderão ser criadas interações entre ocupação urbana e o meio natural, com novas possibilidades de mobilidade para a população e conexão de áreas públicas e de convívio.

Porém, apesar do panorama bastante positivo de ações, ainda exige um elemento estruturador de todas as intervenções, entendido como um sistema integrado de áreas que relaciona a cidade com a seu ambiente enquanto infraestrutura biofísica e social integrante do território.

\section{CONSIDERAÇÕES FINAIS}

A proposta da Infraestrutura verde, entendida como um sistema integrado, conectando áreas naturais ao ambiente urbano e integrando projetos estruturais representa a possibilidade de oferecer um desenho ambiental, cultural e social no território destinada a atender a população, associada aos serviços públicos básicos e obras já em andamento.

A designação da infraestrutura verde é relativamente recente, mas tem uma longa história de antecedentes, enraizada nas múltiplas propostas de ordenamento das áreas verdes que, de forma mais isolada ou sistêmica, foram se desenvolvendo desde a Revolução Industrial objetivando minorar os problemas ambientais e sociais dos espaços urbanos. Apesar da preocupação pela preservação e criação de áreas verdes se confundir com a própria história das cidades, é com as alterações espaciais, sociais e ambientais que esse movimento ganha a expressão que reconhecemos na atualidade (Madureira, 2012).

Esta relação de complementaridade e dependência da população urbana e da cidade é profundamente alterada com as transformações decorrentes, induzindo progressivamente a necessidade de preservar e/ou criar novas áreas que requalifiquem o ambiente, despertando o sentimento de necessidade de espaços livres para o uso dos cidadãos, que cada vez mais consciencializados sobre as más condições de vida exigem progressivamente, condições de apropriação da cidade. 
A proposta da rede da infraestrutura verde no bairro dos Alvarenga funciona como um eixo norteador para as diretrizes de ações que neste momento de grandes intervenções, criariam valores estabelecidos na melhoria da forma urbana, no padrão dos projetos estruturais, na qualidade de vida da população e na conservação ambiental.

\begin{abstract}
"Estamos diante da oportunidade de adequação aos novos parâmetros ambientais consensuados democraticamente e da oportunidade de definir um conjunto de princípios e regras orientadoras para os agentes que constroem e utilizam o espaço urbano" (Lima, 2013).
\end{abstract}

A sociedade começa a mudar a percepção de seu papel passivo diante dos impactos na natureza, seja pelas alterações climáticas, vulnerabilidades físicas, valorização do cotidiano de seu ambiente. Os espaços conflituosos que se estruturou nessa região de expansão urbana que causou severos danos, também guarda um grande potencial que deve ser valorizado.

O estudo da infraestrutura verde, definindo regiões prioritárias à preservação, a conservação e a intervenção de projetos permite criar conexões, acompanhar as transformações e voltar a caracterizar as áreas livres nas orientações pertinentes aos projetos, procurando entender como os processos interagem e reforçam-se mutuamente e relacionam-se com as condições de vida da população.

O Plano Diretor de São Bernardo do Campo prevê a compatibilização das atividades econômicas com o meio ambiente. Para tanto dividiu o Município em macrozonas ${ }^{11}$. A macrozona de maior conflito para o território é onde se localiza o bairro Dos Alvarenga, corresponde a Macrozona Urbana de Recuperação Ambiental, caracterizada pela ocupação urbana irregular na área de proteção aos mananciais. Os objetivos para essa macrozona, além de recuperar ambientalmente parte de seu território impactado, propõem adequar a área ao desenvolvimento estratégico do Município. A Zona Especial de Interesse Estratégico (ZEIE) onde deverão ser implantadas as atividades empresariais dos mais diversos seguimentos necessita de ordenação na ocupação e nos adensamentos urbanos em conformidade com a paisagem e as Legislações ambientais.

\footnotetext{
${ }^{11}$ Macrozona de Vocação Urbana (MVU); Macrozona Urbana de Recuperação Ambiental (MURA); Macrozona de Ocupação Dirigida (MOD); e, Macrozona de Restrição à Ocupação (MRO).
} 
A abordagem da infraestrutura verde, entendida como um sistema que possibilita o agrupamento dos usos, identificando os espaços livres, espaços verdes, diferenciando a tipologia dos espaços construídos e a infraestrutura urbana, tomado como eixo norteador de intervenções, trabalha sobre diagnóstico sistematizado, representa o conjunto de todas as ações em interação, define padrões de crescimento traduzindo seus resultados pela qualidade alcançada para a população.

\section{REFERÊNCIAS BIBLIOGRÁFICAS}

BENEDICT, Mark A., MCMAHON, Edward T. Green infrastrustructure: linking landscapes and communits. Washington, DC: ISLAND PRESS, 2006.

BONDUKI, Nabil. Origens da habitação social no Brasil: arquitetura moderna, lei do inquilinato e difusão da casa própria. São Paulo: Estação Liberdade, 2011.

CAPOBLANCO, João Paulo Ribeiro. Billings 2000. Ameaças e perspectivas para o maior reservatório de água da região metropolitana de São Paulo. Relatório do Diagnóstico Socioambiental Participativo da Bacia Hidrográfica da Billings 1989-99. Instituto Socioambiental, 2002.

CETESB - COMPANHIA AMBIENTAL DO ESTADO DE SÃO PAULO. Relação de áreas contaminadas e reabilitadas no Estado de São Paulo. Disponível em:<http:// www.cetesb.sp.gov.br/areas-contaminadas/relacoes-de-areas-contaminadas/15publicacoes>, 2011.

CSIRO (2007), Urban Resilience .Research Prospectus.A Resilience Alliance Initiative for Transitioning Urban Systems towards Sustainable Futures. CSIRO, Australia - Arizona State University, USA - Stockholm University, Sweden, fev. 2007.

DEÁK, Csaba, SCHIFFER, Sueli Ramos (organizadores). O processo de Urbanização no Brasil. São Paulo: Editora da Universidade de São Paulo, 2010.

DENALDI, Rosana. Assentamentos precários: identificação, caracterização e tipos de intervenção In: BRASIL. Manual do Curso à distância: Plano Local de Habitação de Interesse Social - EAD-PLHIS. Brasília: MCIDADES, 2009, .107-131. 
FERRARA, Luciana Nicolau. Urbanização da natureza: da autoprovisão de infraestruturas aos prjetos de recuperação ambiental nos mananciais do sul da metrópole paulistana. Tese apresentada à Faculdade de Arquitetura e Urbanismo da Universidade de São Paulo, para obtenção de grau do título de Doutor em Arquitetura e Urbanismo, 2013.

FRANCO, Maria de Assunção Ribeiro. Desenho Ambiental. Uma introdução à arquitetura da paisagem com o paradigma ecológico. São Paulo: Annablume / FAPESP, 1997.

FRANCO, Maria de Assunção Ribeiro. Planejamento ambiental para a cidade sustentável. São Paulo: Annablume: FAPESP, 2001.

GOVERNO DO ESTADO DE SÃO PAULO. SECRETARIA DO MEIO AMBIENTE. Política e Gestão de Recursos Hídricos no Estado de São Paulo. São Paulo: A Secretaria, 1993.

IPT. Soluções tecnológicas para Municípios. Instituto de Pesquisas Tecnológicas do Estado de São Paulo, 2013.

ISA - INSTITUTO SOCIOAMBIENTAL. Billings 2000: ameaças e perspectivas para o maior reservatório de água da região metropolitana de São Paulo: relatório do diagnóstico socioambiental participativo da bacia hidrográfica da Billings no período 1989-99 (J.P.R. CAPOBIANCO \& M. WHATELY, orgs). São Paulo: Instituto Socioambiental, 2002.

LINCH, Kevin. A imagem da cidade. São Paulo:Martins Fontes, 1997.

MADUREIRA, Helena. Infra-estrutura verde na paisagem urbana contemporânea: o desafio da conectividade e a oportunidade da multifuncionalidade. In Revista da Faculdade de Letras - Geografia - Universidade do Porto III série, vol. I, 2012, pp. 33 -43.

MARANDOLA Jr.,Eduardo. Novos significados da mobilidade. Revista Brasileira de Estudos de População, São Paulo, v. 25, n. 1, p. 199-200, jan./jun. 2008. Disponível em <http://www.scielo.br/pdf/rbepop/v25n1/v25n1a13.pdf>. Acesso 18 out. 2013.

MÉDICE, Ademir. São Bernardo, Seus Bairros, Sua Gente - Cadernos Históricos I - Seção de Pesquisa e Banco de Dados - SA. 212 - PMSBC, 1981. 
OLIVEIRA, Sonia L.; STAURENGHI, Rosangela. Experiências de Regularização Fundiária no Brasil. Regularização Fundiária em São Bernardo do Campo: São Paulo. Disponível em: http://www.cidades.gov.br/secretarias-nacionais/programasurbanos/biblioteca/regularizacao-undiaria/experienciasde-regularizacao-fundiaria-nobrasil/sp/EXPERIENCIASSAOBERNARDO2007.pdf. Acesso em: 21 Fev.2014.

PLANSERVI - Programa de Transporte Urbano de São Bernardo do Campo, 2004.

PLHIS-PMSBC. PRODUTO FINAL CONSOLIDADO | Maio de 2012 Trabalho co-financiado pelo Ministério das Cidades através da CAIXA pelo contrato de repasse $\mathrm{n}^{\circ}$ : 0236.736-74/2008.

PMAE - PLANO MUNICIPAL DE ABASTECIMENTO DE ÁGUA E ESGOTAMENTO SANITÁRIO, 2010.

PMSBC - PREFEITURA DO MUNICÍPIO DE SÃO BERNARDO DO CAMPO. Sumário de Dados 2012 - Ano Base: 2011. São Bernardo do Campo, 2011.

SANTOS, Rozely Ferreira dos. Planejamento Ambiental: teoria e prática. São Paulo: Oficina de Textos, 2004.

SERPA, Angelo. Espaço público e acessibilidade: notas para uma abordagem geográfica. GEOUSP - Espaço e Tempo, São Paulo, n¹5, 2004.

SETTI, AFF. Análise de intervenção em área de mananciais no município de São Bernardo do Campo: o caso do Programa Bairro Ecológico. Dissertação de Mestrado. São Paulo: Faculdade de Saúde Pública da Universidade de São Paulo, 2008.

TAGNIN, RA. O tratamento da expansão urbana na proteção aos mananciais: o caso da região metropolitana de São Paulo. Dissertação de Mestrado. São Paulo. Escola Politécnica da USP, 2000.

WHATELY, Marussia: SANTORO, P.F.: TAGNIN, R.A. Contribuições para a elaboração de leis específicas de mananciais: o exemplo da Billings. São Paulo: Instituto Socioambiental, 2008. 


\section{Sites}

http://www.ipea.gov.br

http://www.metro.sp.gov.br

http://www.urban-age.net

http://aguasclarasdoriopinheiros.org.br.

http://billingsrepresahistoria.blogspot.com.br/

http://www.cetesb.sp.gov.br/areas-contaminadas/rela\%C3\%A7\%C3\%B5es-de\%C3\%A1reas-contaminadas/19-jardim-das-oliveiras 